\title{
Transformaciones de tenencia y uso de la tierra en zonas del ámbito rural colombiano afectadas por el conflicto armado. El caso de Tibú, Norte de Santander (2000-2010)*
}

\author{
Transformations of Tenancy and Land Use in Rural Areas of Colombia \\ Affected by the Armed Conflict. The Tibú's case, North \\ of Santander (2000-2010) \\ Tranformações de posee e uso de terra em zonas do âmbito rural \\ Colombiano, afetadas pelo conflito armado. O caso de Tibú, \\ no departamento de Norte de Santander (2000-2010)
}

\author{
SONIA URIBE KaFFURE ${ }^{\star \star}$ \\ Observatorio de Restitución y Regulación de Derechos de Propiedad Agraria
}

FeCHA DE RECEPCIÓN: 29 de MAYO de 2013 • FeCHA DE APROBACIÓN: 17 DE SEPTIEMBRE de 2013

Doi: dx.doi.org/10.12804/esj16.1.2014.06

Para citar este artículo: Uribe Kaffure, S. (2013). Transformaciones de tenencia y uso de la tierra en zonas del ámbito rural colombiano afectadas por el conflicto armado. Aproximación desde un estudio de caso. Estudios Socio-Jurídicos, 16(1), 245-287. doi: dx.doi.org/10.12804/esj16.1.2014.06

\section{RESUMEN}

Este artículo describe las transformaciones en la tenencia y uso de la tierra en Tibú (Norte de Santander) entre 2000 y 2010 . Muestra que ellas fueron altamente concentradoras, masivas y generadas sucesivamente por dos vías: una coercitiva, operada por el paramilitarismo y otra, operada por empresarios y comisionistas de la tierra a través de un mercado anómalo y desregulado. Planteo que ambas vías son explicativas del land grab, conducen a fenómenos de acumulación por desposesión y que ninguna de las dos se puede entender sin dar cuenta de un conjunto de diseños institucionales y políticas públicas promovidas desde el Estado.

* El artículo recoge los hallazgos de la autora en desarrollo de su proyecto de investigación para optar al título de Maestría en Estudios Políticos de la Universsidad Nacional de Colombia, bajo la dirección de Francisco Gutiérrez Sanín.

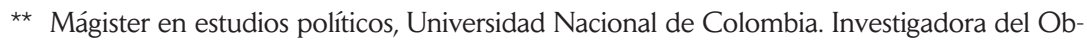
servatorio de Restitución y Regulación de Derechos de Propiedad Agraria. Correo electrónico sonia. uribe@observatoriotierras.org 
Palabras clave: Conflicto armado, land grab, coerción, mercado desregulado, regulaciónn estatal. .

\section{ABSTRACT}

This article describes the changes in land tenure and land use in Tibú (Norte de Santander) between 2000 and 2010. It shows that those changes were highly concentrating, massive, and successively developed in two ways: a coercive one, operated by paramilitaries, and another one, operated by entrepreneurs and other land commissioners through an abnormal and unregulated market. I argue that both ways are explicatives of land grab, conduce to accumulation forms via dispossession, and that neither can be understood without accounting for a set of public policies and institutional designs promoted by the state.

Keywords: armed conflict, land grab, constraint, unregulated market.

\section{RESUMO}

Este artigo descreve as transformações na posse e uso da terra de Tibú (Norte de Santander) entre os anos 2000 e 2010. Mostra que elas foram altamente concentradoras, massivas e geradas sucessivamente por duas vias: uma coercitiva, operada pelo paramilitarismo e outra, operada por empresários e comissionistas da terra através de um mercado anômalo e desregulamentado. Expõe-se que ambas as vias respondem a formas de acumulação por desapropriação e que nenhuma das duas pode se entender sem dar conta de um conjunto de criações institucionais e políticas públicas promovidas desde o Estado.

Palavras- chave: Concentração da propriedade agrária, conflito armado, acumulação por desapropriação, mercado desregulamentado, regulação estatal. 


\section{Introducción}

La inequitativa distribución de los activos rurales es un problema histórico y estructural, que antecede - e incluso explica- los orígenes del conflicto armado que vive el país desde hace más de tres décadas (Fajardo, sf). Dada la magnitud de los fenómenos de abandono y despojo que se han presentado en vigencia de tal periodo de violencia, en la actualidad cobra especial relevancia la reflexión y el análisis sobre la incidencia que este ha tenido en el fenómeno de acumulación-despojo de la propiedad rural y sobre cómo se ha surtido.

Tal reflexión puede contribuir, de un lado, a responder a los desafíos que el país se ha planteado frente a la restitución de tierras y la búsqueda negociada de la paz y, de otro, a entender las relaciones entre inequidad, conflicto y desarrollo, pues, lejos de avanzar hacia procesos de redistribución de los activos rurales, Colombia, de manera sostenida, ha seguido un patrón concentrador de la propiedad agraria, con un vertiginoso impacto en zonas marginales de colonización, duramente afectadas por el conflicto armado (Ibáñez y Muñoz, 2012).

Aunque no existen datos oficiales, se estima que durante el conflicto armado interno en Colombia las tierras rurales abandonadas o despojadas superan las 6.500 .000 hectáreas. ${ }^{1}$ Tal cifra señala cambios significativos en el ordenamiento del mundo rural. Empero, poco sabemos sobre cómo ha transformado esto las estructuras de tenencia y a través de qué mecanismos se han transferido los activos rurales en tales contextos. Se tienen entonces dos interrogantes: ¿qué transformaciones de tenencia y uso de la tierra se han producido en contextos rurales afectados por el conflicto armado en Colombia? y icómo y por qué se produjeron? Estos son los problemas a cuya comprensión espera contribuir el presente artículo.

Respecto del primer interrogante, el artículo muestra que en Tibú, entre los años 2000 y 2010, se produjo una transformación concentradora y masi-

La Comisión Nacional de Seguimiento a la Política Pública de Desplazamiento Forzado estima que entre los años 1980 y 2010 se produjo el abandono y despojo de 6.638.195 hectáreas rurales (Comisión Nacional de Seguimiento..., 2011). Dicha cifra es consistente con la presentada en su momento por la Agencia Presidencial para la Acción Social y la Cooperación Internacional -Acción Social- que calculó las hectáreas rurales abandonadas por las víctimas de desplazamiento en 6.556.978 (Acción Social..., 2010b). 
va de la propiedad rural, evidenciada en una recomposición de la estructura agraria local y un vertiginoso aumento del índice $\mathrm{Gini}^{2}$ de concentración, tanto de tierras como de propietarios. El uso del suelo también ha sufrido importantes transformaciones, manifiestas, por ejemplo, en el aumento de las áreas de cultivos agroindustriales y de explotación minero-energética, en contraposición con la pérdida de áreas de cultivos semipermanentes y bosques naturales.

Respecto del segundo, se proponen y describen dos vías explicativas al fenómeno de despojo-concentración de la tierra, las cuales operaron de manera diferenciada (interpuesta o sucesivamente) y sin aparente vínculo entre sí y sus actores: (i) una vía coercitiva operada por los paramilitares, en la lógica de consolidar dominio territorial, asegurar el territorio, arrasar la base social del enemigo y apropiarse de sus rentas de financiación (Salinas, 2011) y (ii) una vía sin coerción aparente operada por empresarios y comisionistas que, sobre la base de las transformaciones que de facto produjo la acción paramilitar, echaron a andar un anómalo y desregulado mercado de tierras, pese a la existencia de importantes regulaciones destinadas a proteger la tierra de la población campesina y prevenir el despojo (Ley 387 de 1997; Ley 160 de 1994).

Sostengo aquí que ambas vías son explicativas del despojo-acumulación de tierras (land grab) en las últimas décadas, que si bien ha acontecido en el marco y bajo las lógicas del conflicto, se relaciona con asuntos que van más allá de este. Además de que el fenómeno es masivo, se vincula con factores ya identificados por importantes investigadores sobre fallas estatales no solo en la distribución sino, igualmente, en la regulación y los diseños institucionales para definir, asignar y salvaguardar derechos de propiedad agraria (LeGrand, 1988; Reyes, 2009; Gutiérrez, 2012)). Tales fallas han operado históricamente $-\mathrm{y}$ siguen operando en la actualidad-, como incentivo para la apropiación violenta y la indebida acumulación de la propiedad rural (Peña Huertas, Parada Hernández, Zuleta Ríos, en este volumen).

El artículo se desarrolla en cinco apartados: el primero ilustra brevemente los datos y métodos de la investigación; el segundo ubica geográficamente 
el caso de estudio y presenta algunos datos sobre los cambios en la estructura predial rural, la evolución de los índices Gini de concentración de la tierra y cambios en el uso del suelo, durante el periodo analizado; el tercero esboza algunos elementos centrales de la línea explicativa propuesta; el cuarto describe las vías coercitiva y no coercitiva de despojo-concentración de la propiedad agraria en Tibú y, finalmente, el quinto apartado presenta algunas reflexiones específicas respecto del caso analizado y otras más amplias relacionadas con el carácter estructural que reviste la concentración de la propiedad agraria en el marco del conflicto armado.

\section{Datos y métodos}

Desde la metodología de estudio de caso, la investigación se centró en documentar y explicar las transformaciones de tenencia y uso que en el marco del conflicto armado se produjeron en Tibú durante el periodo 2000-2010. Para ello, además de la revisión documental, se acudió al mapeo temporal y espacial de datos y hechos relevantes en relación con (i) cambios en la estructura predial rural, (ii) identificación del contexto de las transformaciones y (iii) mecanismos de transformación y actores o agentes operarios del despojo-concentración.

Los datos específicos y el diseño metodológico de la investigación, se resumen en las figuras 1 y $2 .^{3}$

\section{Las transformaciones concentradoras}

Tibú se localiza en el extremo nororiental del departamento de Norte de Santander y hace parte de la región del Catatumbo (mapa 1). Dos rasgos derivados de su localización, como son el carácter de frontera internacional y el hacer parte del corredor estratégico que conecta las regiones Caribe

3 El trabajo de campo para esta investigación se realizó durante el segundo semestre del año 2010. La autora agradece a Myriam Hernández Sabogal y al equipo regional Norte de Santander del Proyecto Protección de Tierras y Patrimonio de la Población Desplazada, por su apoyo en la labor de terreno y sus contribuciones al desarrollo de la investigación. 


\section{y Llanos Orientales, le han conferido una especial importancia geopolítica para los actores del conflicto.}

Figura 1. Datos y métodos de la investigación

\begin{tabular}{|c|c|c|c|c|}
\hline \multicolumn{5}{|c|}{$\begin{array}{l}\text { ¿Qué transformaciones de uso y tenencia de la tierra se han presentado } \\
\text { en ámbitos rurales afectados por el conflicto armado y cómo explicarlas? }\end{array}$} \\
\hline \multirow{4}{*}{ 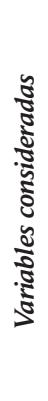 } & \multirow{4}{*}{$\begin{array}{l}\text { Estructuras de uso y } \\
\text { vivienda y sus cam- } \\
\text { bios } \\
\end{array}$} & \multicolumn{2}{|c|}{ Dependiente } & $\begin{array}{l}\text { Externa (variable con- } \\
\text { textual) }\end{array}$ \\
\hline & & $\begin{array}{c}A \\
\text { (Vía coercitiva) }\end{array}$ & $\begin{array}{c}\text { B } \\
\text { (Vía NO coercitiva) }\end{array}$ & \multirow{3}{*}{$\begin{array}{l}\text { Políticas de intervención } \\
\text { estatal en el territorio; } \\
\text { Normas regulatorias del } \\
\text { derecho de propiedad, } \\
\text { intereses y proyectos } \\
\text { económicos para el te- } \\
\text { rritorio }\end{array}$} \\
\hline & & $\begin{array}{l}\text { Ocurrencia de aban- } \\
\text { dono y despojo de } \\
\text { la tierra a causa de la } \\
\text { violencia }\end{array}$ & $\begin{array}{l}\text { Concentración de la } \\
\text { propiedad agraria y } \\
\text { compra venta masiva } \\
\text { de tierras }\end{array}$ & \\
\hline & & \multicolumn{2}{|c|}{ ¿Relación entre vías y sus actores? } & \\
\hline 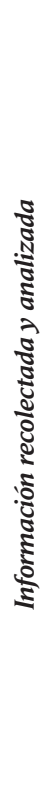 & $\begin{array}{l}\text { Estadisticas Castra- } \\
\text { les: a) Cambios en } \\
\text { la cantidad y tama- } \\
\text { ño de predios rura- } \\
\text { les y b) cobertura de } \\
\text { rangos prediales re- } \\
\text { pecto del área mu- } \\
\text { nicipal } \\
\text { Índices GINI } \\
\text { Regulación sobre } \\
\text { las tierras rurales }\end{array}$ & $\begin{array}{l}\text { - Relación entre } \\
\text { censo poblacional } \\
\text { y desplazamiento } \\
\text { forzado } \\
\text { - Tierras y territorios } \\
\text { abandonados a cau- } \\
\text { sa de la violencia. } \\
\text { (RUPTA) } \\
\text { - Informes de Dere- } \\
\text { chos sobre predios } \\
\text { y territorios (aplica- } \\
\text { ción de la Ley } 387 \\
\text { de } 1997 \text { y decretos } \\
\text { reglamentarios) }\end{array}$ & $\begin{array}{l}\text { Solicitudes de enaje- } \\
\text { nación y transferencia } \\
\text { de predios cobijados } \\
\text { por medidas de pro- } \\
\text { tección patrimonial: } \\
\text { - Transferencia de } \\
\text { derechos de pro- } \\
\text { piedad } \\
\text { - Naturaleza de los } \\
\text { predios transferi- } \\
\text { dos (privado, bal- } \\
\text { dío, otras) } \\
\text { - Identificación quie- } \\
\text { nes venden y quie- } \\
\text { nes compras }\end{array}$ & $\begin{array}{l}\text { - Dinámica del conflicto } \\
\text { armado } \\
\text { - Índices de desarrollo } \\
\text { municipal } \\
\text { - Presencia de cultivos } \\
\text { ilícitos } \\
\text { - Planes de ordenamien- } \\
\text { to y desarrollo territo- } \\
\text { rial Municipal } \\
\text { - Políticas de desarrollo } \\
\text { rural en los niveles te- } \\
\text { rritoririal y nacional } \\
\text { - Proyectos de desarro- } \\
\text { llo rural de Tibú desde } \\
\text { lo local y lo nacional } \\
\text { - presencia de cultivos } \\
\text { agroindustriales } \\
\text { - Itervención territorial } \\
\text { - Histórico de títulos y } \\
\text { solicitudes de títulos } \\
\text { mineros para el muni- } \\
\text { cipio de tibú }\end{array}$ \\
\hline \multicolumn{5}{|c|}{ Entrevista a actores sociales, políticos, institucionales y empresariales en el territorio } \\
\hline \multicolumn{5}{|c|}{ Mapeo de las transformaciones } \\
\hline
\end{tabular}

Fuente: Elaboración propia. 
Con base a el Informe de Derechos sobre Predios y a las solicitudes para vender o transferir la tenencia:

1) Se identificaron, analizaron y mapearon las transacciones sobre predios (2005-2010)

2) Se filtraron y mapearon aquellas transacciones realizadas sobre predios titulados (baldíos) paradicho periodo

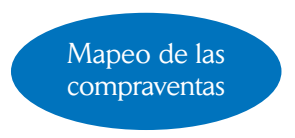

Se construyó una base de datos:

- Ubicación del predio

- Nombre del predio

- Área

- Tradición (tiene o no)

- Número de folio de Matrícula Inmobiliaria

- Estado de folio: abierto, cerrado

- Número predial o cédula catastral

- Modo de adquirir: compraventa, sucesión, compraventa de derechos sucesorales, adjudicacieon de baldíos, sentencia judicial, declaración mejoras, declaración fundación, otros

- ¿Existe falsa tradición?

- ¿Se abrió con base en folios anteriores?

- ¿Segregación o englobe nuevos folios?

- ¿Inicia tradición con adjudicación de baldíos?

* Realizado por el equipo regional Norte de Santander del proyecto Protección de Tierras y Patrimonio de la Población Desplazada (PPTP)

** Realizado por la investigadora con base en información del PPTP-Norte de Santander

Fuente: Elaboración propia.

De modo muy general y con fines ilustrativos, enuncio aquí varios hitos que marcan la dinámica local del conflicto armado en Tibú: la presencia del ELN y del EPL desde finales de la década de los 70, la introducción de cultivos de coca a mediados de la década de los $80,{ }^{4}$ la irrupción de las FARC y su rápido predominio como actor armado a finales de los 80 , la incursión y posterior consolidación del dominio paramilitar entre $1999^{5}$ y

4 A mediados de la década de los 80 , Colombia se convirtió en uno de los principales productores y exportadores de cocaína. Particularmente, las FARC se consolidaron en zonas de expansión de cultivos de uso ilícito, ejerciendo inicialmente el cobro de tributos y regulación de precios. El corregimiento de La Gabarra, en Tibú, fue una de las zonas en las que las FARC se posicionaron como un regulador externo, tanto de la producción como de la comercialización de la coca. Gutiérrez y Barón, señalan como para el caso de Tibú (y a diferencia de los dispositivos utilizados en el sur del país: control estricto a la sobre producción, censos, retenes y decomiso de coca no reportada, fijación de precio para compra, obligación de venta directa a las FARC según precios del secretariado), este grupo armado reguló las relaciones sociales de la economía cocalera a través de mecanismos como: a) condicionamiento de la siembra de coca al uso de determinada extensión de los predios para cultivos de pancoger y b) control y cobro de impuestos, pero libre venta del campesino a intermediarios. Sin embargo, en la década de los 90, hubo un giro en el involucramiento de las FARC, que extendió la red de alianzas con el mundo del narcotráfico y empezó a participar tanto en embarques como en la provisión y protección de rutas de producción y comercialización (Gutiérrez y Barón, 2008).

5 El bloque Norte de las AUC se conformó en 1999 bajo el mando de Salvatore Mancuso. La finalidad de las autodefensas en esta región tenía dos fines claramente definidos: arrebatar el 


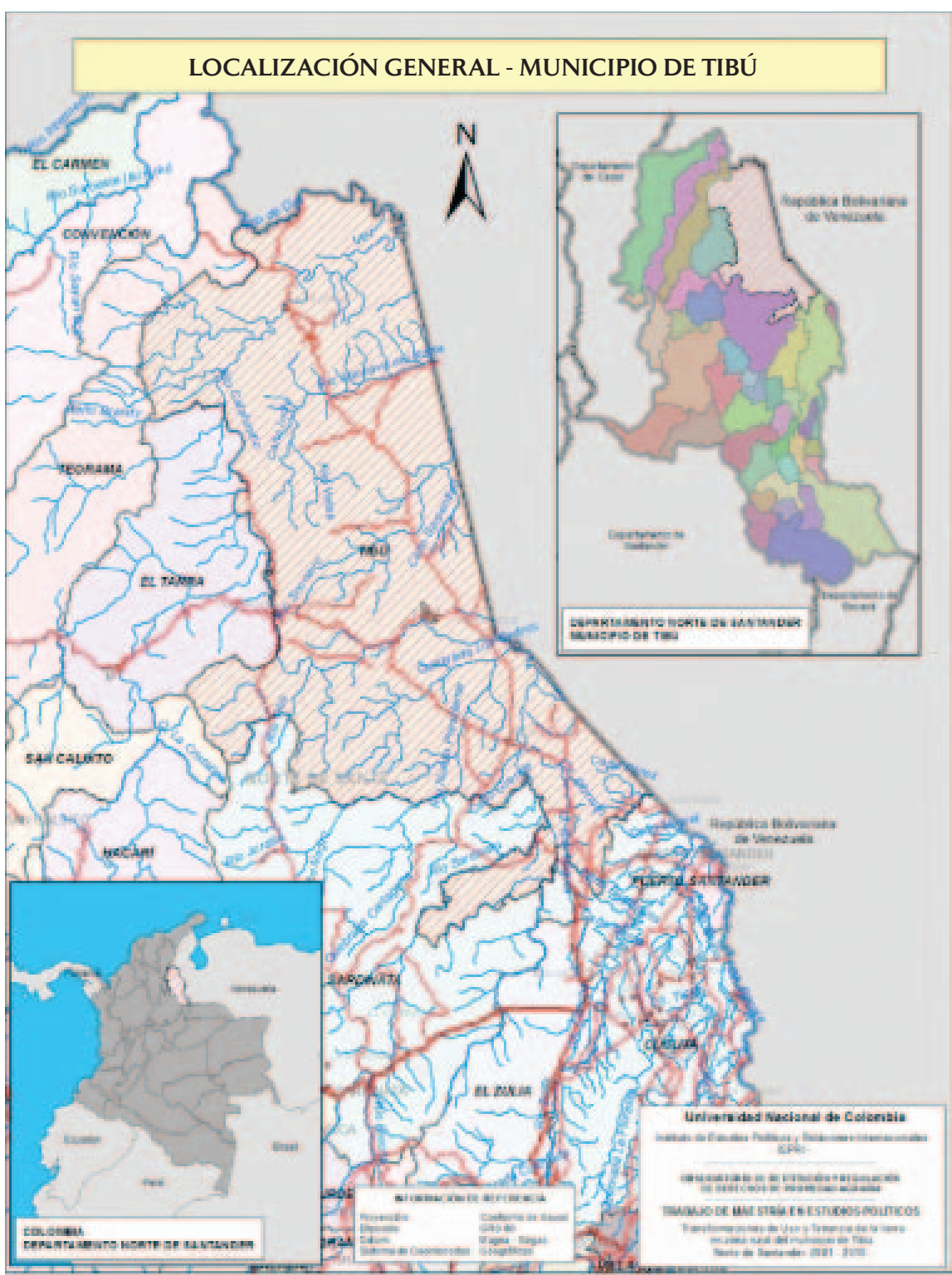

Fuente: Cartografía base IGAC. Elaboración propia.

dominio territorial a las FARC, arrasar su 'base social', y controlar la economía de los cultivos ilícitos. De hecho, "por su compromiso con el narcotráfico progresivamente se convirtió en uno de los más importantes bloques de las AUC". Recuperado de http://www.verdadabierta.com/editores/multimedias/estructuras/estructuras_intro.html. Hoy se sabe que la entrada de las AUC a Norte de Santander contó con el apoyo y coordinación de algunas unidades de las fuerzas militares acantonadas allí (El Ejército abrió..., 2009; "La fuerza pública...", 2012). 
2004 (año en el que se surtió la desmovilización de los Bloques Norte y Catatumbo ${ }^{6}$ ), y el periodo de post-desmovilización paramilitar en el que grupos como las 'Águilas Negras' se (re)posicionaron en los espacios de antiguo dominio de las AUC y entraron en disputa con las FARC por las rentas y rutas de micro y macro-tráfico (Asociación para la promoción..., 2008; Programa Presidencial para los Derechos Humanos..., 2010; Pérez, 2006; Misión de Observación ..., s.f.).

Los datos sobre las transformaciones de tenencia y uso de la tierra que presenta este artículo se relacionan con los cambios que se dieron entre los años 1999 y 2000 respecto a la estructura predial rural, el uso productivo de la tierra y la evolución del índice de concentración Gini. Tales transformaciones tienen como telón de fondo tanto el periodo de hegemonía paramilitar como el de post-desmovilización de este grupo armado, es decir, el periodo de transición guerra-paz paramilitar. ${ }^{7}$

\subsection{Cambios en la estructura predial rural ${ }^{8}$}

Durante el período 1999-2009 la cobertura predial rural de Tibú aumentó en 14.635 hectáreas (tabla 1). Si bien no hay información al respecto, es bastante probable que dicho crecimiento se consiguiera mayormente en detrimento de la cobertura de bosque natural, la cual decreció en 14.056 hectáreas entre 2002 y 2009 (tabla 6).

6 La desmovilización del Bloque Norte se surtió el 10 de diciembre del año 2004, en la Finca 'Brisas del Sardinata', ubicada en el corregimiento Campo Dos del municipio de Tibú. La desmovilización de 1.434 hombres estuvo encabezada por Salvatore Mancuso (Presidencia de la República..., 2006). El hecho fue reportado en diversos medios de comunicación. Ver, por ejemplo, Arranca desmovilización... (2004).

7 Paola García (comunicación personal, 2013), investigadora del Observatorio de Restitución Regulación de Derechos de Propiedad Agraria, afirma que ha habido un aprovechamiento de la paz en el proceso de despojo y concentración de la propiedad en Colombia. El caso de Tibú parece ajustarse a tal hipótesis, pues es en el año 2005, durante el periodo post-desmovilización, cuando se activa el mercado de tierras que este artículo describe como la vía de mercado de despojo-acumulación.

8 Es importante señalar, en términos metodológicos, que los valores presentados para el año 2009 en cobertura y número de predios por rango predial corresponden a los datos de la actualización catastral adelantada por el IGAC ese mismo año. Esto significa que los cambios en cobertura o número de predios pueden estar reflejando variaciones producidas a lo largo de la década y no necesariamente en ese año específico. Los datos completos sobre cobertura y número de predios del período 1999-2009 se presentan al final del documento (Anexos 1 y 2). 
Tabla 1. Dinámica de la cobertura predial rural de Tibú 1999 y 2009

\begin{tabular}{|c|c|c|c|c|c|}
\hline \multirow[b]{2}{*}{ Rango predial (ha) } & \multicolumn{2}{|c|}{1999} & \multicolumn{2}{|c|}{2009} & \multirow{2}{*}{$\begin{array}{c}\text { Diferencia } \\
\text { (ha) } \\
2009-1999\end{array}$} \\
\hline & Área (ha) & $\%$ & Área (ha) & $\%$ & \\
\hline$<10$ & 2.582 & 1 & 2.463 & 0,9 & -119 \\
\hline $10-50$ & 45.537 & 17,6 & 47.115 & 17,3 & 1.578 \\
\hline $50-200$ & 128.180 & 49,7 & 132.217 & 48,6 & 4.037 \\
\hline $200-1.000$ & 37.675 & 14,6 & 40.398 & 14,8 & 2.723 \\
\hline$>1.000$ & 43.496 & 16,8 & 49.793 & 18,3 & 6.297 \\
\hline Total & 257.470 & 100 & 271.986 & 100 & 14.635 \\
\hline
\end{tabular}

Fuente: Elaboración propia con base en estadísticas catastrales IGAC y Proyecto Protección de Tierras y Patrimonio de la Población Desplazada, Norte de Santander.

Como muestra la tabla 1, todos los rangos de tamaño predial aumentaron su cobertura en el decenio analizado, excepto el rango $<10$ hectáreas (el menor de la clasificación predial aquí presentada), cuya cobertura disminuyó en 119. El aumento más grande lo obtuvo el rango $>1.000$ hectáreas, con 6.297, seguido por el rango 50-200 hectáreas con 4.037, y los rangos 200-1.000 hectáreas y 10-50 hectáreas con 2.723 y 1.578, respectivamente. La dinámica anual de la cobertura predial rural durante el decenio 19992009 señala que los años que experimentaron mayor variación (pérdidas y ganancias en cobertura), fueron 2000, con 3.131 hectáreas; 2001, con 1.994 hectáreas, 2006, con 1.796 hectáreas; 2008, con 1.659 hectáreas; y 2009, con 19.366 hectáreas (gráfico 1). ${ }^{9}$

De otro lado, el número total de predios rurales de Tibú aumentó de 4.765 en 1999 a 8.794 en 2009, es decir que en una década se crearon 4.029 nuevos predios en el municipio. Todos los rangos de tamaño predial aumentaron su número de predios, no obstante, el incremento en 3.983, experimentado por el rango $<10$ hectáreas (el menor de la clasificación), resultó extraordinario, comparado con el de los demás (tabla 2).

De acuerdo con lo anterior, es claro que los cambios más significativos en cobertura y número de predios durante el decenio 1999-2009 se dieron en el menor rango de la clasificación predial $(<10$ hectáreas). El aumento 
Gráfico 1. Pérdidas y ganancias anuales en cobertura (ha) por rango predial (1999-2009)

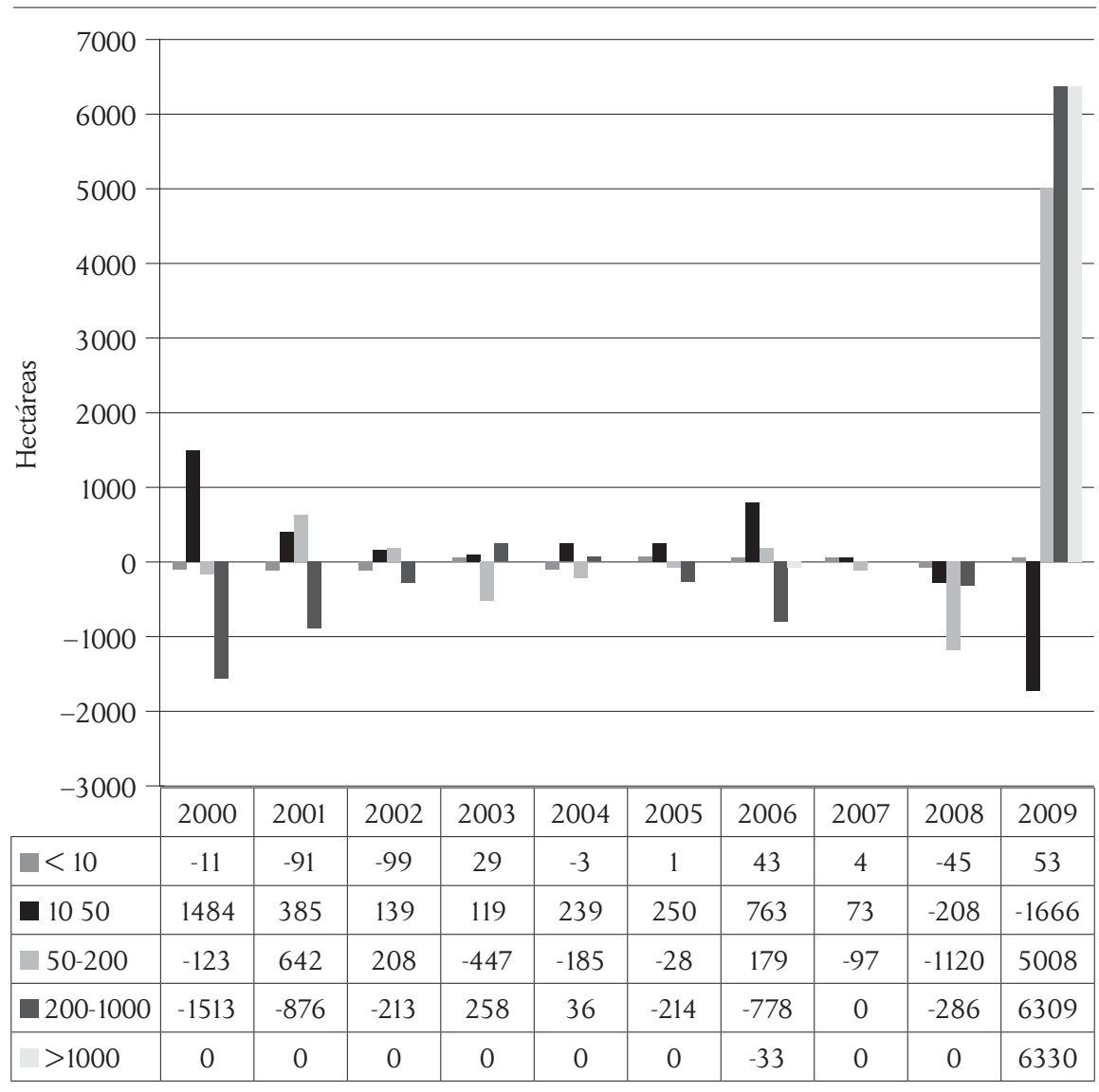

Fuente: Elaboración propia con base en Estadísticas Catastrales IGAC (2002, 2009), Acción Social-PPTP (2010a).

en el número de predios del rango $<10$ hectáreas ocurrió simultáneamente con la contracción de su cobertura, lo cual significa que los predios de ese rango se hicieron más pequeños (en 1999 existían 1.633 predios en un área de 2.562 hectáreas; ya en 2009 habían 5.616 predios en un área de 2.463 hectáreas). ${ }^{10}$

10 Esto es lo que algunos agraristas llaman "-micro-minifundización" de la propiedad agraria. Ver, por ejemplo, Fajardo (s.f.). 
Tabla 2. Dinámica del número de predios rurales de Tibú, 1999 y 2009

\begin{tabular}{|c|c|c|c|c|c|}
\hline & \multicolumn{2}{|c|}{1999} & \multicolumn{2}{c|}{2009} & \multirow{2}{*}{$\begin{array}{c}\text { Diferencia } \\
\text { 2009-1999 }\end{array}$} \\
\hline Rango & Número & $\%$ & Número & $\%$ & 3.983 \\
\hline 1010 & 1.633 & 34,2 & 5.616 & 63,8 & 30 \\
\hline $50-200$ & 1.602 & 33,6 & 1.632 & 18,5 & 2 \\
\hline $200-1.000$ & 131 & 29,1 & 1.393 & 15,8 & 12 \\
\hline$>1.000$ & 8 & 0,16 & 143 & 1,6 & 2 \\
\hline Total & 4.765 & 100 & 8.794 & 100 & 4.029 \\
\hline
\end{tabular}

Fuente: elaboración propia con base en estadísticas catastrales IGAC (2002) y actualización catastral (IGAC I, 2009), Proyecto Protección de Tierras y Patrimonio de la Población Desplazada (PPTP), y PPTP Norte de Santander.

De otro lado, si bien el aumento en el número de predios mayores de 200 hectáreas fue tan solo de 25 , su cobertura se incrementó en por lo menos 12.600 hectáreas (tablas 1 y 2 ).

\subsection{Evolución del índice Gini}

La dinámica predial de Tibú se compagina coherentemente con el vertiginoso aumento del índice Gini municipal, tanto de tierras como de propietarios, cuyos valores, si bien han estado muy por debajo de las medias departamental y nacional durante el periodo 2000-2011, se incrementan de manera tal que logran reducir la brecha y ajustarse claramente al patrón concentrador del país (gráficos 2 y 3 ).

El comportamiento de los índices Gini de tierras y propietarios de Tibú, durante la mayor parte del periodo 2000-2011, es relativamente estable; no obstante, en los últimos años del lapso descrito dichos índices experimentaron incrementos significativos. El Gini de tierras aumentó de 0,50 en 2010 a 0,67 en 2011, mientras que el Gini de propietarios, aumentó de 0,58 en 2009 a 0,73 en 2010 y, posteriormente, a 0,79 en 2011 (IGAC, 2012) (gráfico 4).

El aumento de los índices Gini puede estar relacionado con la actualización de los datos catastrales adelantada por el IGAC en el año 2009. Sin embargo, su comportamiento es congruente con la dinámica predial ante- 


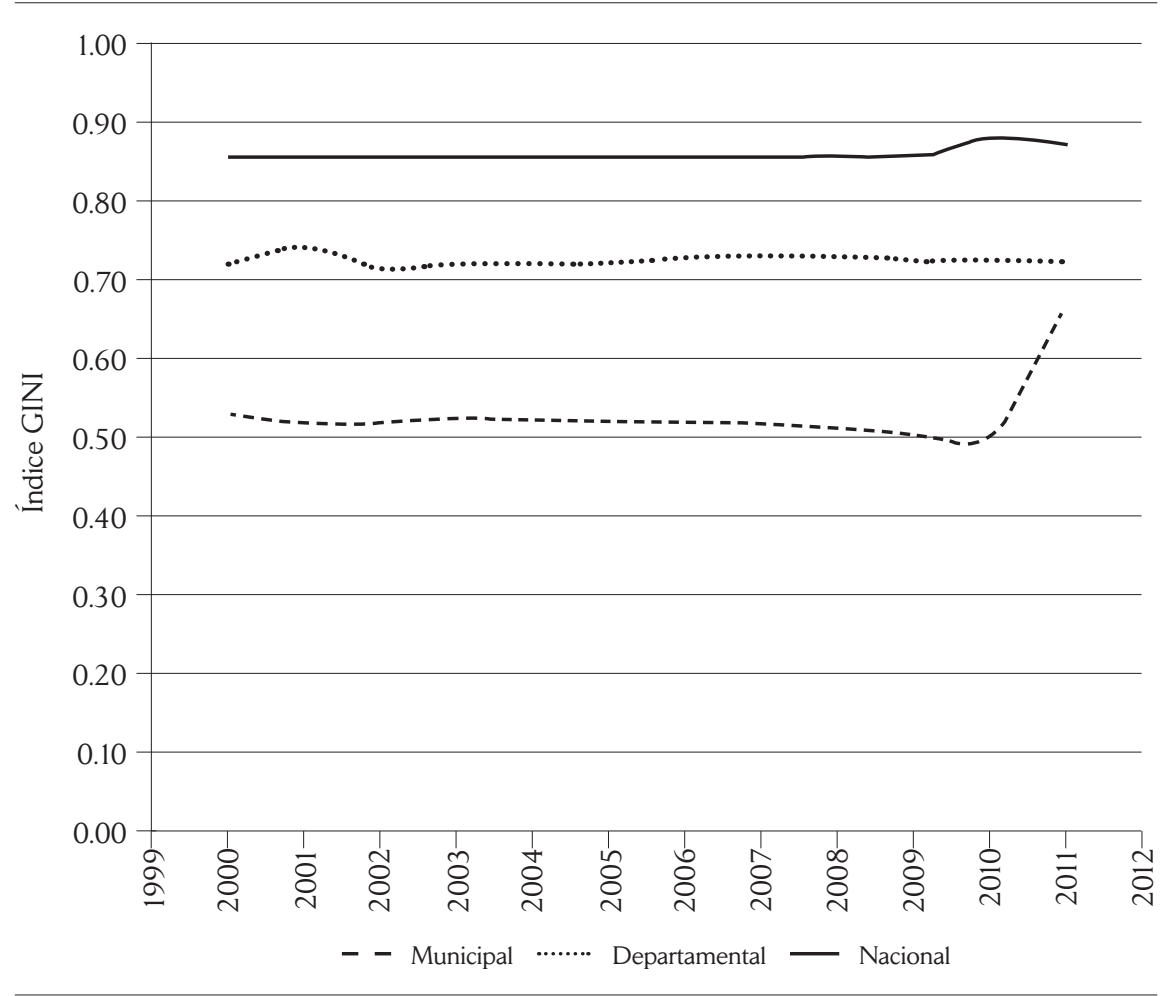

Fuente: Elaboración propia con base en el Atlas de Distribución de la Propiedad Rural en Colombia, IGAC (2012).

riormente expuesta y con la de transacciones de dominio que se presenta más adelante, en desarrollo de la vía de mercado anómalo y desregulado. Ahora bien, según el Atlas de la propiedad rural del IGAC (2012), la dinámica predial rural de Tibú muestra que el dinamismo predial estuvo en la mediana propiedad, la cual ganó tanto en número de predios como en cobertura. Esos datos difieren de los obtenidos en esta investigación, aunque ambos provienen de fuente oficial (IGAC). Es importante destacar que los índices Gini de tierras y propietarios del mismo atlas evidencian concentración, por lo que los datos aquí presentados parecen ser más acordes con tal fenómeno. De todos modos, lo que de también podría estar señalando la información del atlas es que la concentración de la propiedad rural se puede dar, además, a través de la mediana propiedad y que su predominio no 


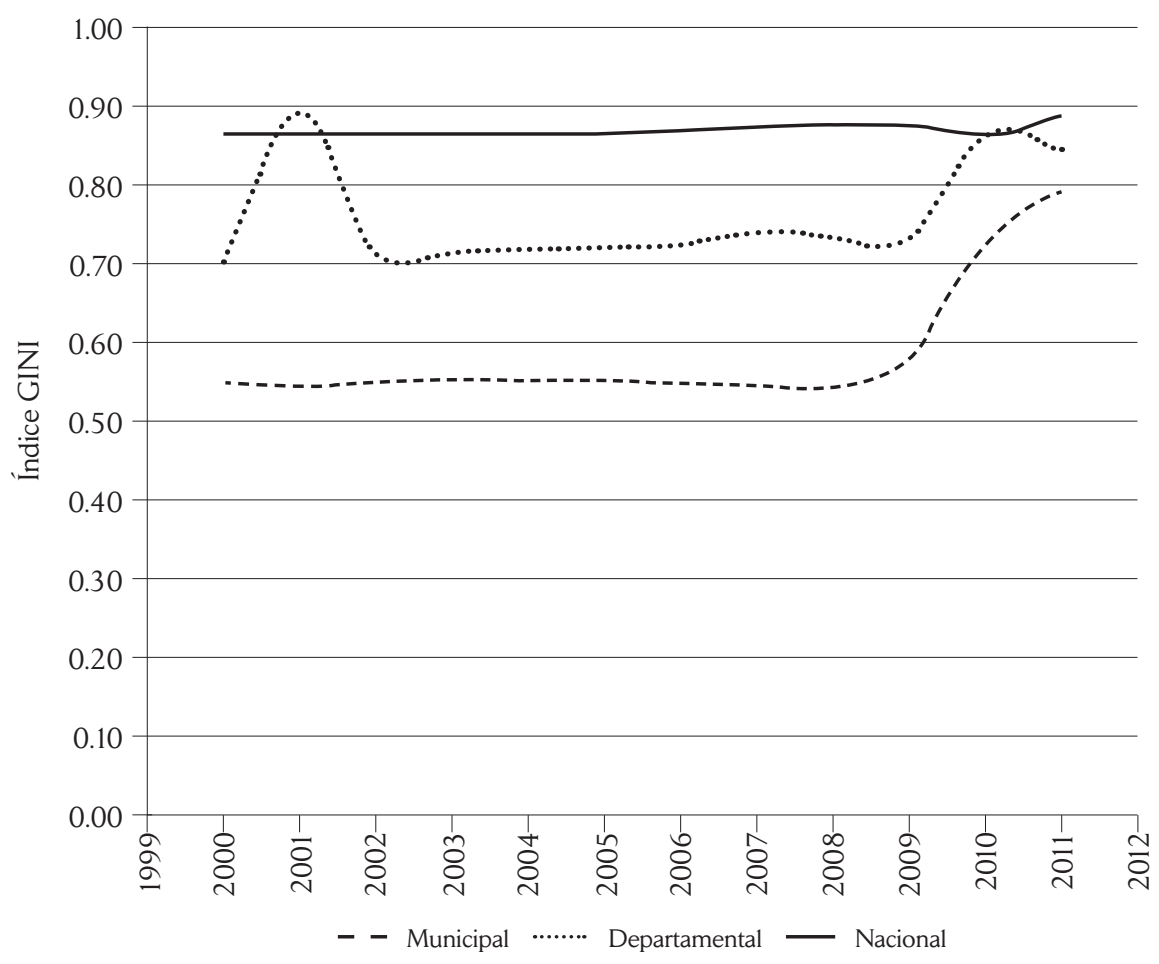

Fuente: Elaboración propia con base en el Atlas de Distribución de la Propiedad Rural en Colombia, IGAC (2012).

\begin{abstract}
es necesariamente evidencia de un proceso de democratización o mejor distribución de los activos rurales, sino más bien de nuevas formas o lógicas de latifundización, que incluyen el acaparamiento de las tierras por uso."
\end{abstract}

11 Sobre el particular, en informe elaborado por Yamile Salinas Abdala (2011) se señala: "Además de la concentración de la tierra, se evidencia que en la última década se incrementó el monopolio de su uso en actividades mineras, petroleras y agroindustriales por parte de grandes grupos económicos nacionales, con poder político para incidir en la formulación y adopción de políticas y leyes a su favor. Dicha concentración se da mediante compras propias de sus filiales y a través de figuras que no implican la transferencia de dominio". Para Salinas, esta situación es claramente palpable en zonas de consolidación territorial en las que el Estado ha introducido e incentivado la expansión de proyectos de explotación minero energético y agro-industrial, como es el caso de Tibú (conversación personal, 2012). Sobre el tema de concentración por uso, ver también el trabajo de Carlos Suescún Barón (2012). 


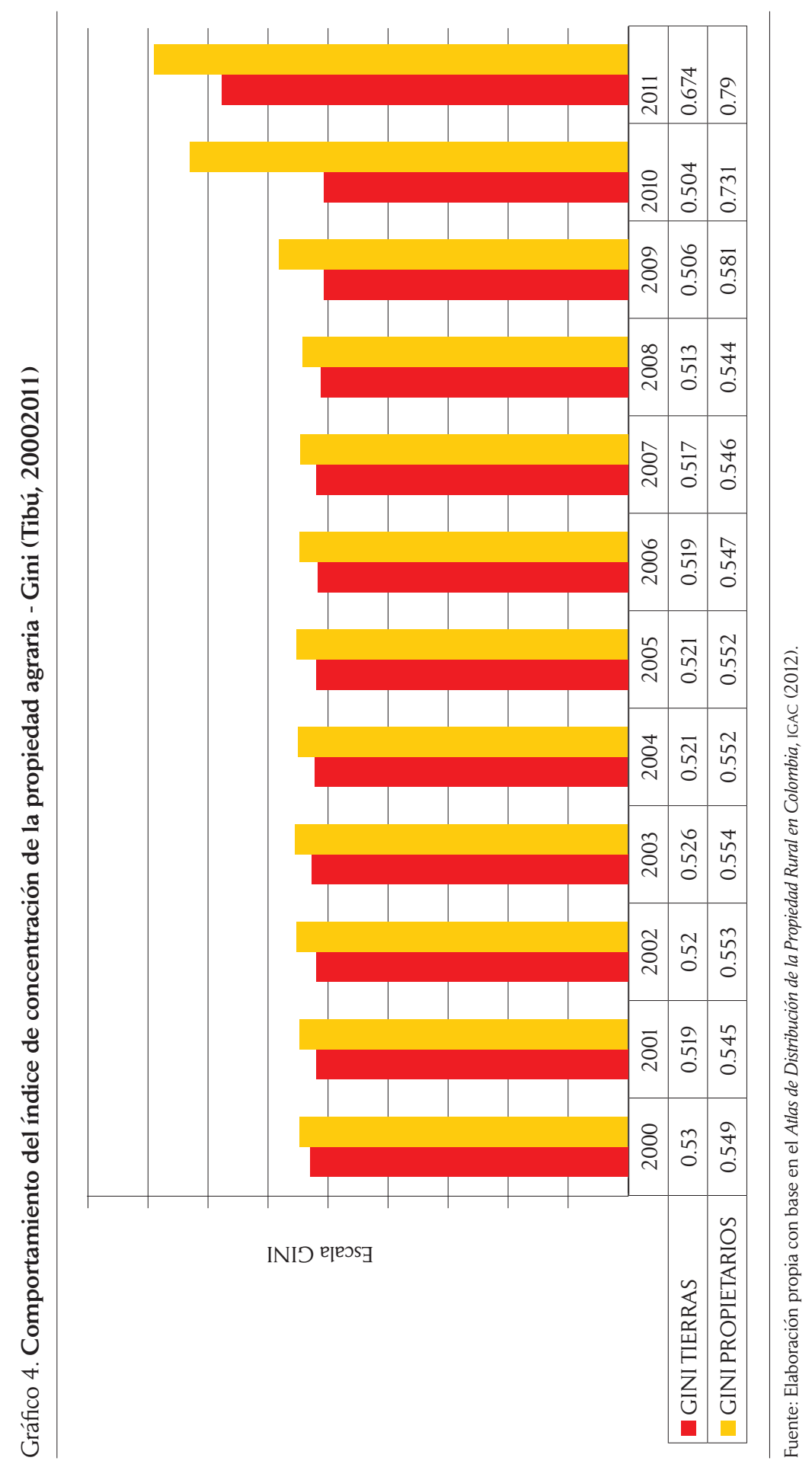

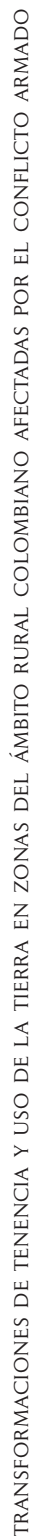




\subsection{Cambios en el uso productivo de la tierra}

Durante el periodo 2002-2009 se produjeron en Tibú importantes transformaciones en el uso del suelo, evidentes en los cambios de cobertura de la vegetación natural y antropogénica. En ocho años, la cobertura de bosque natural disminuyó en 14.056 hectáreas, en tanto que la de cultivos transitorios y coca decreció en 2.172 y 2.520 hectáreas, respectivamente; en contraste, la cobertura de pastos manejados y cultivos agroindustriales de palma aceitera aumentó en 30.012 y 6.077 hectáreas, respectivamente (tabla 3). Aunque no hay cifras claras, se estima que la palma en Tibú alcanzó más de 14.000 hectáreas para 2012.

Respecto del uso del subsuelo en Tibú, las áreas destinadas a exploración y producción minero-energética ocupan importantes porciones del área territorial municipal (mapa 2). En 2008 el área comprometida con solicitudes mineras ascendía a 110.208 hectáreas, mientras que el área destinada a títulos mineros abarcaba 71.313 hectáreas. Respecto a la actividad de hidrocarburos, datos de Ingeominas (2008) y de la Agencia Nacional de Hidrocarburos (2010) indican que por lo menos 215.521 hectáreas de la superficie municipal están en explotación. La afectación por solicitudes de explotación o títulos minero-energéticos representan el 81,12\% del área total municipal (Acción Social, PPTP, 2010a, pp. 76-82).

\section{Elementos para una lectura de la acumulaciòn-despojo en el estudio de caso}

Desde su conformación como república, Colombia ha seguido un patrón concentrador de la propiedad rural. Sabemos que tal fenómeno se relaciona, por lo menos, con los siguientes elementos: (i) la estructura agraria bimodal de tenencia ${ }^{12}$ que, si bien fue heredada de la Colonia, se

12 El Land Tenure Center de la Universidad de Wisconsin define la estructura agraria como "el patrón de distribución de la tierra entre sus dueños. La estructura puede ser unimodal, en la que una mayor parte de las tierras está distribuida entre medianos propietarios, o bimodal, en la que la mayor parte de las tierras está distribuida entre pocos grandes propietarios y una pequeña parte de las tierras está en manos de muchos pequeños propietarios" (Bruce, 2000). Así, la estructura bimodal de tenencia permite la coexistencia del latifundio y el minifundio, pero supone una tensión o pugna por el predomino de la grande o la pequeña propiedad. 
Tabla 3. Dinámica de uso del suelo de Tibú 2002 y 2009

\begin{tabular}{|c|c|c|c|c|c|}
\hline $\begin{array}{c}\text { Cobertura } \\
\text { general }\end{array}$ & $\begin{array}{l}\text { Cobertura } \\
\text { específica }\end{array}$ & Uso principal & $\begin{array}{c}\text { Área (ha) } \\
2002\end{array}$ & $\begin{array}{c}\text { Área (ha) } \\
2009\end{array}$ & $\begin{array}{c}\text { Diferencia 2009- } \\
2002 \text { (ha) }\end{array}$ \\
\hline \multirow{2}{*}{$\begin{array}{l}\text { 1. Territorios } \\
\text { artificializados } \\
\text { (zonas } \\
\text { urbanas) }\end{array}$} & \multirow{2}{*}{$\begin{array}{l}\text { 1.1. Zonas } \\
\text { urbanas }\end{array}$} & 1.1.1. Tejido urbano & 230 & 230 & 0 \\
\hline & & $\begin{array}{l}\text { 1.1.3. Centros pobla- } \\
\text { dos }\end{array}$ & 53 & 53 & 0 \\
\hline \multirow{7}{*}{$\begin{array}{l}\text { 2.Territorios } \\
\text { agrícolas }\end{array}$} & $\begin{array}{l}\text { 2.1. Cultivos } \\
\text { anuales o } \\
\text { transitorios }\end{array}$ & $\begin{array}{l}\text { 2.1.1. Cultivos transito- } \\
\text { rios (Arroz, yuca, maíz, } \\
\text { plátano) }\end{array}$ & 6.684 & 4.511 & -2.172 \\
\hline & \multirow{3}{*}{$\begin{array}{l}\text { 2.2. Cultivos } \\
\text { permanentes }\end{array}$} & 2.2.1. Cacao y otros & 4.105 & 3.276 & -829 \\
\hline & & 2.2.2. Palma de aceite & 0 & 6.077 & 6.077 \\
\hline & & 2.2.3. Ilícitos & 3.295 & 774 & -2.520 \\
\hline & \multirow[b]{2}{*}{ 2.3. Pastos } & 2.3.1. Pastos limpios & 24.010 & 54.022 & 30.012 \\
\hline & & $\begin{array}{l}\text { 2.3.2. Pastos enmale- } \\
\text { zados o enrastrojados }\end{array}$ & 27.246 & 8.621 & -18.624 \\
\hline & $\begin{array}{l}\text { 2.4. Áreas } \\
\text { agrícolas } \\
\text { heterogéneas }\end{array}$ & $\begin{array}{l}\text { 2.4.3. Mosaico de cul- } \\
\text { tivos, pastos y espacios } \\
\text { naturales }\end{array}$ & 105.281 & 109.637 & 4.355 \\
\hline \multirow{3}{*}{$\begin{array}{l}\text { 3. Bosques } \\
\text { y áreas } \\
\text { seminaturales }\end{array}$} & \multirow{2}{*}{ 3.1. Bosques } & $\begin{array}{l}\text { 3.1.1. Bosque natural } \\
\text { basal }\end{array}$ & 4.785 & 5.038 & 252 \\
\hline & & $\begin{array}{l}\text { 3.1.2. Bosque natural } \\
\text { fragmentado basal }\end{array}$ & 87.500 & 73.443 & -14.056 \\
\hline & $\begin{array}{l}\text { 3.2. Áreas con } \\
\text { vegetación } \\
\text { arbustiva y/o } \\
\text { herbácea }\end{array}$ & $\begin{array}{l}\text { 3.2.1. Arbustos y ma- } \\
\text { torrales }\end{array}$ & 2.493 & 0 & -2.493 \\
\hline \multicolumn{3}{|l|}{ Total } & 265.686 & 265.686 & \\
\hline
\end{tabular}

Fuente: Acción Social-PPTP (2010a).

fortaleció tempranamente en vigencia de la República, (ii) los fallidos intentos por normar la excesiva acumulación de la propiedad y la decisión de los centros de poder de resolver la tensión sobre el acceso y control de los activos rurales a través de la adjudicación de baldíos, y no mediante una política redistributiva; (iii) la acción y presencia intermediada del Estado en los niveles regional y local ${ }^{13}$ que ha dado lugar a formas arbitrarias

13 Gutiérrez (2010) señala que "La relación entre el Estado colombiano y las élites regionales 


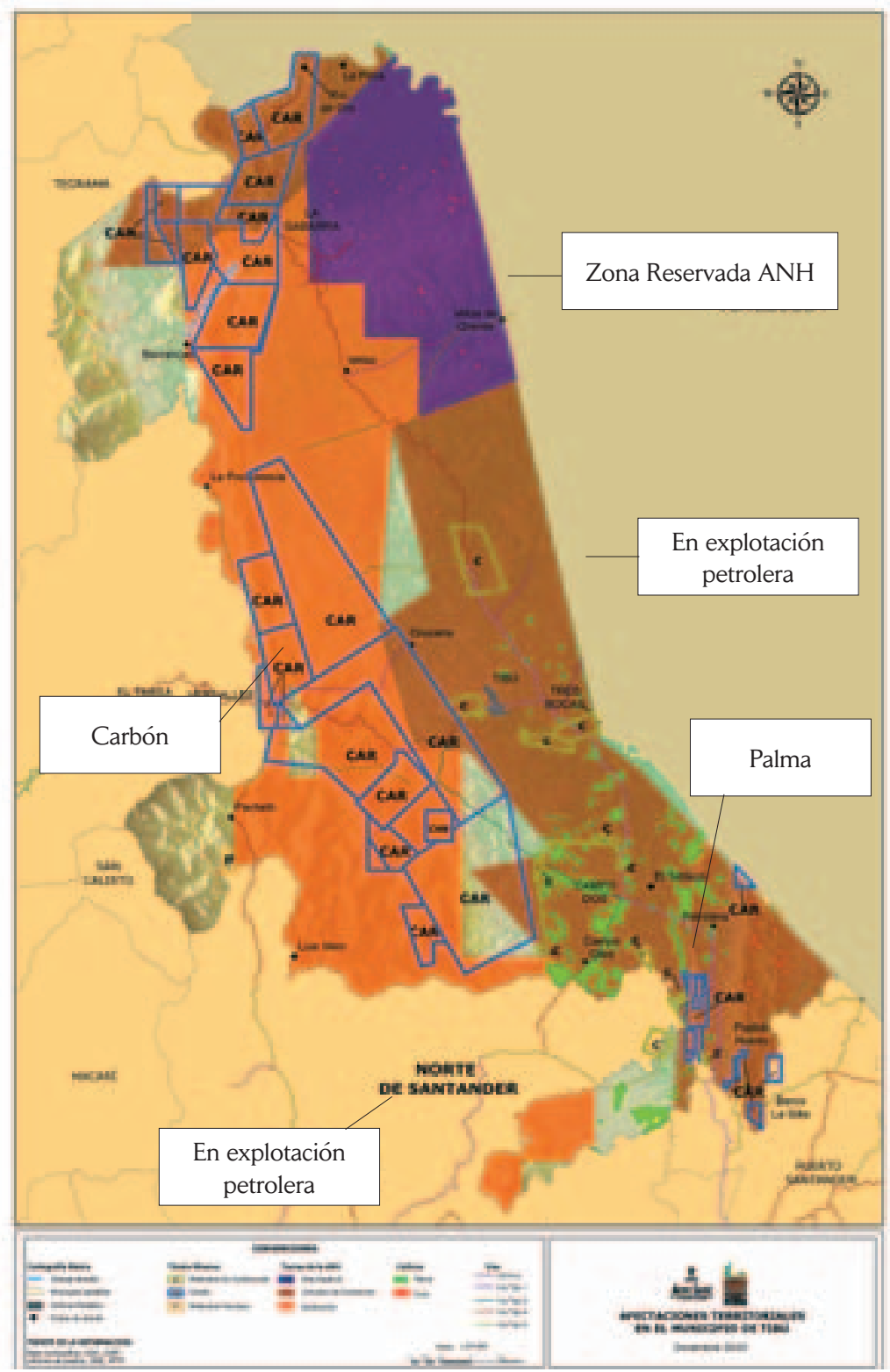

Fuente: adaptación de mapa procesado por Acción social PPTP (2010) según fuentes: CCI del Ministerio de Agricultura: cultivos de palma; SIMCI - UNODC: cultivos de coca; $\mathrm{ANH}$ : tierras reservadas de la $\mathrm{ANH}$; Ingeominas: títulos mineros; IGAC: cartografía, escala 1:100.000.

está caracterizada por un modelo de intermediación; es decir, hay un centro que coordina y gobierna a las regiones a través de las élites regionales y locales". 
de asignación de los derechos de propiedad (Reyes, 1988) y (iv) la íntima relación entre tierra y poder político del que se han valido las élites locales y regionales para mantener su statu quo e imponer hábilmente sus intereses particulares, como si se tratase de los intereses generales del desarrollo y la modernización. ${ }^{14}$ Todos estos elementos siguen vigentes en la actualidad.

De otro lado, la investigación social ha identificado varios elementos que le han impreso características especiales al conflicto armado colombiano en relación con la lucha por la tierra -como son las coaliciones regionales anti-insurgentes que promovieron la conformación de ejércitos privados, el surgimiento del narcotráfico como fuente de financiación de los grupos armados y la compra masiva de tierras por parte de narcotraficantes y testaferros, la incorporación de las autodefensas como grupo paramilitar con capacidad de dominio y apropiación territorial y la regulación estatal del conflicto, especialmente a través de las guerras contrainsurgente y antinarcóticos. Sabemos además que el conflicto armado tiene particulares y diversas expresiones regionales. Empero, poco sabemos sobre los mecanismos a través de los cuales ha operado el proceso de concentración de la propiedad rural, siendo pioneros en ello los trabajos de LeGrand (1998, p. 285) y Reyes (1978). Es justo esa la línea de trabajo a la que espera aportar este artículo.

Además de los elementos anteriormente referidos, la línea argumentativa que propongo (figura 3) toma como referentes conceptos que permiten plantear el problema del despojo y la concentración de la propiedad agraria desde una perspectiva más amplia que la del derecho internacional humanitario, desde la que ha sido abordado con frecuencia: En primer lugar, el concepto de acumulación por desposesión de David Harvey, pues claramente el proceso de concentración de la propiedad agraria en el caso de Tibú operó y se constituyó a partir del detrimento, el menoscabo, la usurpación y el despojo perpetrados por el paramilitarismo. Ese fenómeno resultó fundamental para mercantilizar la tierra de modo posterior (concentración vía mercado). Para Harvey, la regulación o no del Estado resulta fundamental en los proceso de acumulación por desposesión, y ciertamente en el caso de Tibú, pese a que existían medidas jurídicas específicas para la

14 "[...] el problema de la tierra tiene dimensiones mucho más vastas y complejas que el simple problema técnico de aumentar la producción o modernizar el latifundio. La lucha por la tierra es parte de un conflicto centenario por la supervivencia y la identidad, contra quienes identifican sus propios intereses como los intereses generales del desarrollo y la modernización" (Reyes, 1988). 


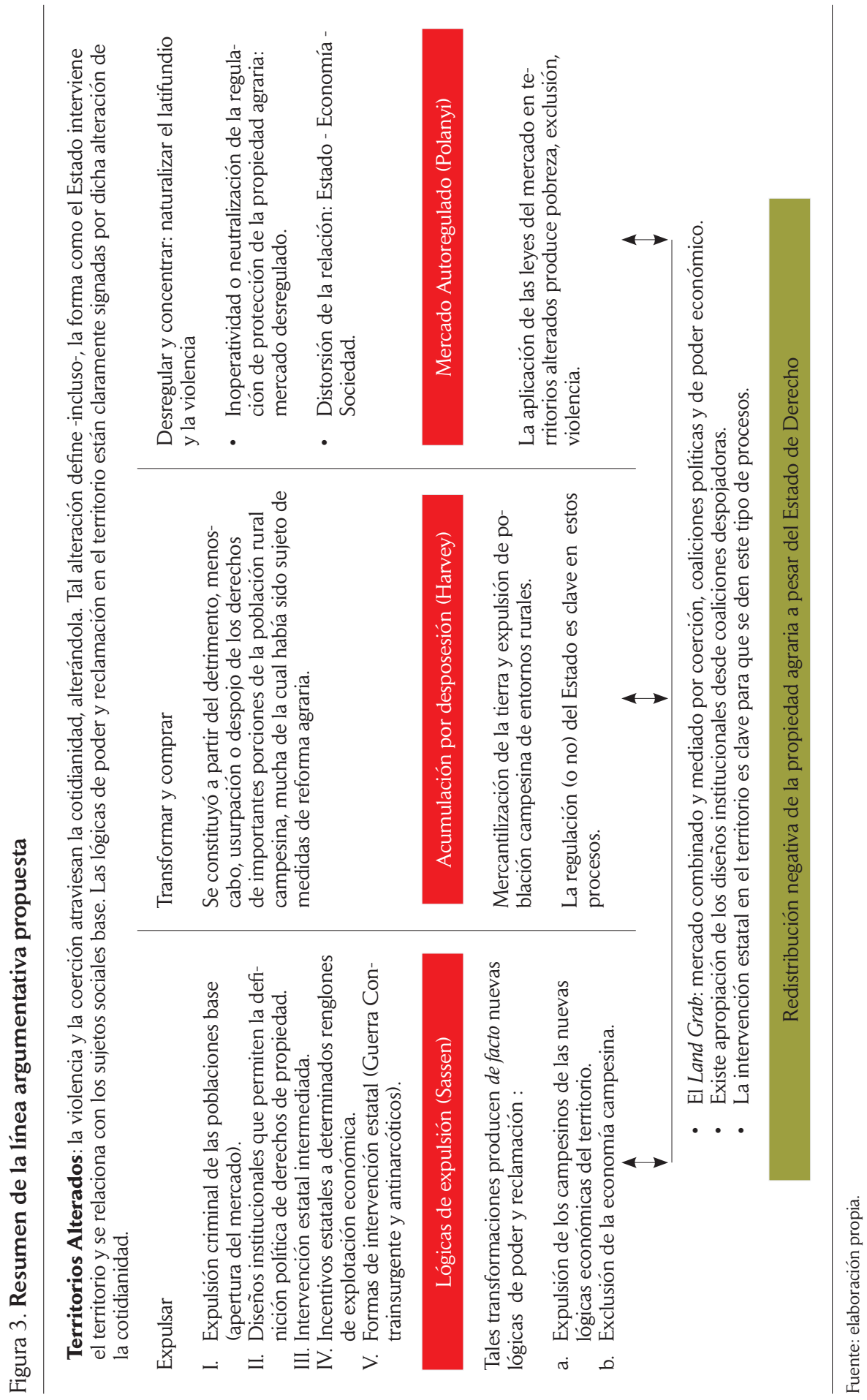


prevenir el despojo de tierras y restricciones para acumular unidades agrícolas familiares, estas quedaron neutralizadas y operó de facto y sin restricción un mercado desregulado que transformó de manera formal las estructuras de tenencia y el uso productivo de la tierra valga decir que en su concepto de acumulación por desposesión, Harvey no tiene en cuenta dos elementos clave que juegan en el land grab colombiano: la mediación de la coerción y los intereses políticos y coaliciones. En segundo lugar, el desplazamiento, el abandono y el despojo de tierras rurales producidos por el paramilitarismo y las coaliciones concentradoras, son de tal magnitud y han generado tales impactos en el reordenamiento del mundo rural que no cabe menos que señalar la existencia de zonas espurias en las que, mediante la expulsión criminal de la población base, se reordenó la tenencia de la tierra. La transformación por vía de tales lógicas de expulsión es profunda y escapa a la mirada del desplazamiento forzado desde el mero derecho internacional humanitario. Dado el carácter masivo, continuo y sistemático del desplazamiento forzado, tal fenómeno parece ajustarse de mejor manera a conceptos como el de Saskia Sassen sobre lógicas de expulsión-exclusión, las cuales producen de facto nuevas lógicas de reclamación y poder territorial. Esas nuevas lógicas se traducen en el contexto rural colombiano -tal como se describe en desarrollo de la vía coercitiva y de mercado propuestas en este artículo- en la exclusión por expulsión de la economía campesina tradicional. ${ }^{15}$

Finalmente, cobran especial relevancia los planteamientos de Karl Polanyi sobre mercado no regulado y bienes ficticios, pues, como mostraré en el caso de Tibú, se produjeron transformaciones masivas, estructurales y desreguladas (del uso y la tenencia de la tierra), con una consecuente distorsión de la relación Estado-sociedad, que no puede menos que acentuar la pobreza, la exclusión y la violencia.

A partir de los referentes antes mencionados, sostengo aquí que las transformaciones en la tenencia y el uso de la tierra para el caso de estudio se produjeron en un contexto territorial profundamente alterado. Propongo llamar

15 "Tras la desmovilización del grupo paramilitar en la región, campesinos e indigenas intentaron volver a sus predios pero se llevaron una sorpresa. La riqueza de sus tierras es a la vez una maldición, dicen. A su regreso encontraron que las tierras eran disputadas algunas por las bandas criminales para controlar el negocio del narcotráfico; otros encontraron sembradíos extensos de palma de aceite, y muchos vieron varias empresas mineras extrayendo carbón. Lo que no entienden, dice Adriana*, es cómo las empresas de carbón obtienen de forma rápida los títulos mineros cuando durante por lo menos 60 años comunidades enteras le han solicitado la titulación de la propiedad sin respuesta" (Laguado Nieto, 2013). 
territorios alterados aquellos en los que su cotidianidad (incluida la forma en la que el Estado hace presencia en él), fue o se halla (de manera prolongada) atravesada por la presencia de actores armados en el territorio y por el uso hegemónico de la violencia y la coerción como patrón predominante de su accionar territorial. De ahí que, independientemente de que no se tenga evidencia de una conexión entre las vías explicativas de la transformación concentradora de la propiedad agraria, se haga innegable el hecho de que la vía coercitiva paramilitar fue fundamental para el aprovechamiento posterior que hiciere el mercado anómalo -y fraudulento en muchos casos-.

Ni la acumulación por desposesión, ni la exclusión por expulsión criminal de la población rural base, ni la distorsión de las relaciones Estadosociedad-mercado son problemas que puedan ser abordados desde el mero derecho internacional humanitario. El fenómeno de concentración-despojo en el marco del conflicto tiene, de suyo, viejos y nuevos problemas relacionados con la inequitativa distribución de los activos rurales y el sistema político. Si otrora la concentración de la propiedad se edificó sobre fallas de regulación estatal, las transformaciones de uso y tenencia por despojoacumulación que se han producido en el marco del confito armado tienen asidero en esas viejas fallas (no resueltas hasta nuestros días) y otras nuevas, como la inserción desregulada del modelo económico en zonas alteradas por las vías de coerción y las formas como el Estado ha concesionado funciones básicas - como la seguridad- en el territorio

Así, en medio del conflicto Colombia ha experimentado fenómenos masivos de distribución negativa de la propiedad rural, sin que en tiempos de paz haya podido revertir la acumulación, ni una distribución positiva (de ricos a pobres). De acuerdo con Lipton (2009), es frecuente que los Estado se enfrente a la dificultad de establecer si dan prioridad al derecho de propiedad (interés particular) sobre el de igualdad (interés general). Para que haya un equilibrio, los Estados deben poder saber en qué momento histórico darán prioridad a uno o a otro. Para dicho autor, un momento clave en el que la igualdad debe prevalecer, es cuando la acumulación de la tierra se ha dado por fraude o violencia, cuando se presentan violaciones masivas a los derechos humanos y cuando hay aumentos dramáticos de la desigualdad. Sin duda, ese parece ser el caso de Colombia. Pero más allá de estas consideraciones, hay dos razones fundamentales para pensar en la urgente necesidad de adelantar acciones redistributivas de la propiedad 
agraria, más allá de las previstas en la justicia transicional -y desde la perspectiva del derecho internacional humanitario-: (i) las transformaciones igualitarias son pro-desarrollo (Berry, 2012) y (ii) mantener la coalición concentradora, es mantener la vía de subdesarrollo persistente (Francisco Gutiérrez, comunicación personal, 2013).

\section{Los micro-mecanismos de despojo-concentración}

\subsection{La vía coercitiva}

El accionar paramilitar en Tibú fue altamente punitivo ${ }^{16}$, produjo vaciamiento del territorio, promovió el repoblamiento rural y transformó de facto la tenencia.

Con la llegada de los paramilitares la vida nuestra cambió. El pan de cada día eran los muertos: en el 2000, cuando entraron, hicieron varias masacres y el miedo se apoderó de todo el mundo; a muchos nos dijeron que teníamos que irnos, otros salieron corriendo antes de recibir la orden de salida [...] Yo dejé tirada la tierra en 2003 porque estaban matando mucha gente [...] primero me fui para Venezuela porque mi esposa tiene familia allá y luego nos vinimos para Cúcuta. Yo no supe nada de la tierra hasta el 2008 porque un señor me dijo que la tierra me la habían invadido y que estaban sembrándole palma [...] (Uribe Kaffure, entrevista a campesino desplazado de Tibú 2010).

De acuerdo con las cifras oficiales del Registro Único de Población Desplazada-RUPD-, el acumulado de población expulsada de Tibú entre los años 1995 y 2009 supera las 31.000 personas. Tal afectación sugiere casi un vaciamiento poblacional del territorio, si se tiene en cuenta que la población municipal proyectada por el DANE para 2009 se estimó en 35.374 habitantes y que el reporte de recepción poblacional para dicho periodo fue de tan solo 3.111 personas. La dinámica anual de afectación

16 "El imponente paisaje de El Catatumbo, (...) está marcado también por una historia de horror. Durante los últimos diez años, 114.000 personas entre campesinos e indígenas salieron desplazados durante la violencia paramilitar, otras 11.200 personas fueron asesinadas en masacres, 600 más están desaparecidas y 400 líderes fueron asesinados. (El Iguano' condenado por masacres..., 2010). 
por desplazamiento forzado con respecto a la población municipal censada y proyectada por el DANE se presenta en la tabla 4.

Tabla 4. Dinámica de expulsión y recepción poblacional de Tibú (1995-2009)

\begin{tabular}{|c|c|c|c|c|}
\hline Año & $\begin{array}{c}\text { Población municipal } \\
\text { (DANE) }\end{array}$ & $\begin{array}{c}\text { Población } \\
\text { expulsada (RUPD) }\end{array}$ & $\begin{array}{c}\text { Pob. expulsada/ } \\
\text { Pob. Municipal \% }\end{array}$ & $\begin{array}{c}\text { Población recepcionada } \\
\text { (SIPOD-RUPD) }\end{array}$ \\
\hline 1995 & 35.249 & 1.650 & 4,7 & 0 \\
\hline 1996 & 35.499 & 350 & 1 & 235 \\
\hline 1997 & 35.769 & 74 & 0,2 & 41 \\
\hline 1998 & 36.059 & 243 & 0,7 & 30 \\
\hline 1999 & 36.210 & 5.101 & 14,1 & 98 \\
\hline 2000 & 36.319 & 2.242 & 6,2 & 92 \\
\hline 2001 & 35.939 & 4.589 & 12,8 & 679 \\
\hline 2002 & 35.589 & 4.871 & 13,7 & 891 \\
\hline 2003 & 35.229 & 3.012 & 8,5 & 208 \\
\hline 2004 & 34.842 & 2.516 & 7,2 & 169 \\
\hline 2005 & 34.773 & 2.771 & 8 & 145 \\
\hline 2006 & 34.889 & 1.803 & 5,2 & 140 \\
\hline 2007 & 35.042 & 1.137 & 3,2 & 58 \\
\hline 2008 & 35.211 & 622 & 1,8 & 3.111 \\
\hline 2009 & 35.374 & 338 & 1 & 100 \\
\hline & Total & 31.319 & & 302 \\
\hline
\end{tabular}

Fuente: Censos y Proyecciones Poblacionales (DANE), Registro Único de Población Desplazada (Acción Social, corte de información a 30 de noviembre de 2010), tabla adaptada de Acción Social-PPTP (2010a).

La información del RUPD muestra dos valores máximos de desplazamiento para el municipio: el primero, en 1999, con 5.101 desplazados (cifra equivalente al $14 \%$ de la población municipal proyectada por el DANE para dicho año) y el segundo, durante el periodo 2001-2003, en el que 12.472 personas fueron expulsadas de sus hogares. Sin embargo, es importante señalar que durante el periodo 2004-2007 se presentaron eventos anuales de desplazamiento que afectaron a más de mil personas. En los años 2008 y 2009, se observa un decrecimiento importante del desplazamiento, aunque se mantiene la expulsión de población (ver tabla 4 y figura 4).

Los datos sobre desplazamiento forzado, homicidios y abandono de tierras, presentan máximos valores durante el periodo de hegemonía paramilitar, tal como muestran los gráficos 5, 6 y la figura 4 . 
En la voz de actores locales, la vía coercitiva paramilitar es descrita de la siguiente manera (Uribe Kaffure, entrevista a dos campesinos que actualmente residen en Cúcuta y que fueron desplazados de sus predios en zona rural de Tibú, durante los años de hegemonía paramilitar, 2010):

Ellos sacaron la gente y en algunos casos simplemente tomaron posesión de la tierra. Trajeron mucha gente de fuera, especialmente de Córdoba y Magdalena, que trabajaba para ellos en lo de la coca y les asignaron los predios de la gente que sacaron. Mucha de esa gente no tenía papeles de la tierra porque estaban esperando las titulaciones del Estado, otros, sí.

Aquí le decían a la gente "me vende la tierra o le compro la viuda". Ya se sabía que el que no acatara las ordenes de esa gente lo mataban, entonces uno nada más firmaba. A otros les decían que por ser auxiliadores de la guerrilla tenían que entregar la tierra y los hacían firmar la escritura, pero el castigo era que no les daban nada por ella y se tenían que ir de la zona.

\subsection{La vía de mercado anómalo y desregulado}

Esta vía operó sobre las transformaciones que de facto produjo la vía coercitiva. Mediante un dinámico y desregulado mercado de tierras, se concentró la tenencia y se favoreció el cambio del uso de la tierra. Esto se produjo pese a la existencia de - por lo menos- dos medidas regulatorias específicas que se le oponían: de un lado, la prohibición de concentrar unidades agrícolas familiares (UAF), establecida en la Ley 160 de 1994, y de otro, la existencia de medidas de protección patrimonial de las que trata la Ley 387 de 1997 (y sus decretos reglamentarios), dirigidas justamente a proteger las tierras abandonadas por la población desplazada en el marco del conflicto armado y prevenir su despojo.

El mapa $3{ }^{17}$ presenta una serie multianual que geo-referencia las operaciones de compraventa de predios en Tibú durante el periodo 20052010. ${ }^{18}$ Dicho mapa ilustra el dinamismo del mercado desregulado de tierras que operó pese a las restricciones derivadas de las medidas de

17 La serie de mapas fue realizada en 2010 por el equipo regional Norte de Santander del Proyecto Protección de Tierras y Patrimonio de la Población Desplazada-Acción Social.

18 El periodo del dinamismo del mercado en Tibú coincide con el fenómeno concentrador señalado por Ibáñez y Muñoz (2012): “Durante el periodo comprendido entre 2000 y 2009, la propiedad rural se concentró aún más, en particular a partir de 2005, la tendencia se acrecentó debido no solo al incremento del tamaño de los predios ya existentes, sino también a la adquisición de nuevos predios por los mismos propietarios". 


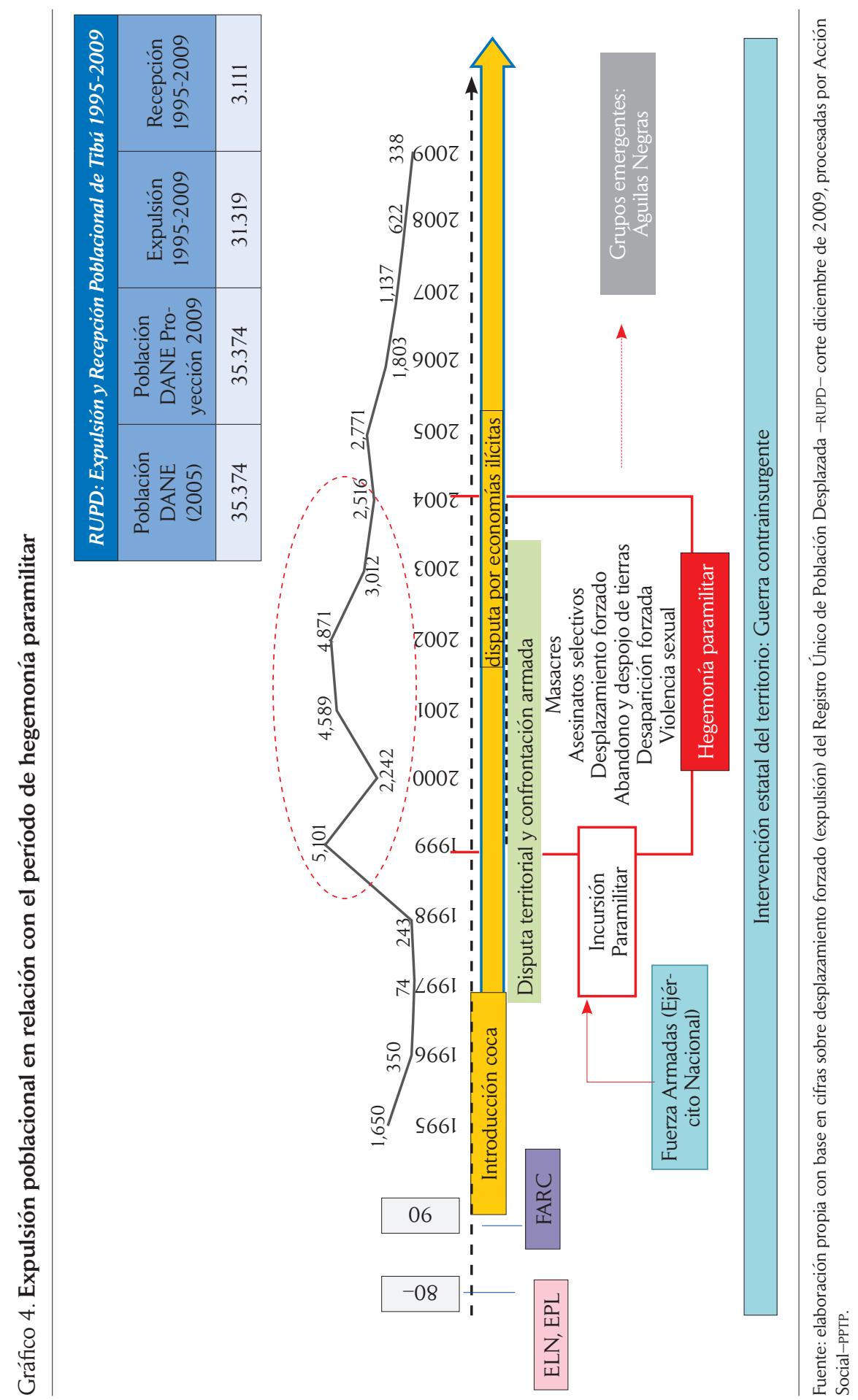




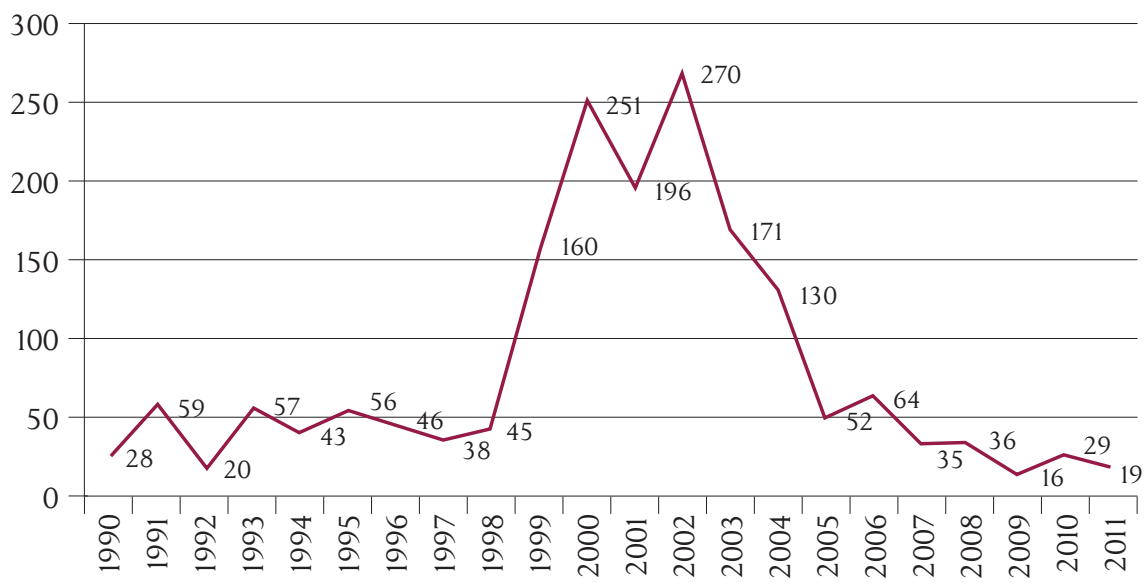

Fuente: Policía Nacional, procesado del Observatorio del Programa Presidencial de DH y DIH, datos extraídos del sistema IDH.

protección patrimonial establecidas en la Ley $387^{19}$ durante el periodo de post-desmovilización paramilitar.

La anuencia del Estado en el proceso de apropiación y concentración indebida que operó por esta vía se manifiesta en dos hechos: la inobservancia o poco activismo de sus agencias e instituciones, frente al fenómeno de compraventa masiva de tierras, y el incentivo a la instauración indiscriminada de proyectos extensivos e intensivos de uso del suelo, que entraron en competencia anómala con la pequeña y mediana economía campesina, tradicionalmente productora de alimentos ${ }^{20}$.

19 En entrevista realizada en 2010 a una ex funcionaria de la Gobernación de Norte de Santander, quien lideró la implementación y seguimiento a las medidas de protección, manifestó: "Tampoco nos imaginamos que hacer eso nos fuera a generar tantos problemas [...] como usted sabe, cuando hay protección uno debe vigilar que no se den compraventas por la fuerza o ventas por debajo del justo precio de la tierra, y la verdad es que meternos con eso fue todo un problema, primero, porque no teníamos cómo saber cuándo un predio se estaba transfiriendo en tales condiciones, segundo, porque nos presionaban mucho diciendo que estábamos frenando el mercado de las tierras y el desarrollo de la región porque había inversionistas de afuera, especialmente de cultivos de palma que querían hacer empresa en Tibú y, además de eso, porque en mi caso particular recibí amenazas y me tuve que ir de la Gobernación porque realmente era mucha presión".

20 "Según el conocimiento de hechos de primera mano en la región a través de testimonios de víctimas que fueron acompañados y orientados por el PPPT en las rutas de protección de tierras, uno de los mayores compradores de tierras fue identificado con el nombre de CARLOS MARIO PELÁEZ DANGOND, quien llegó a la región identificándose como representante de la empresa Bioagroindustrial, acompañado de aproximadamente cuarenta ciudadanos de Córdoba que andaban armados (presumiblemente paramilitares) y fungían como sus escoltas. Con la misma modalidad descrita párrafos atrás, 


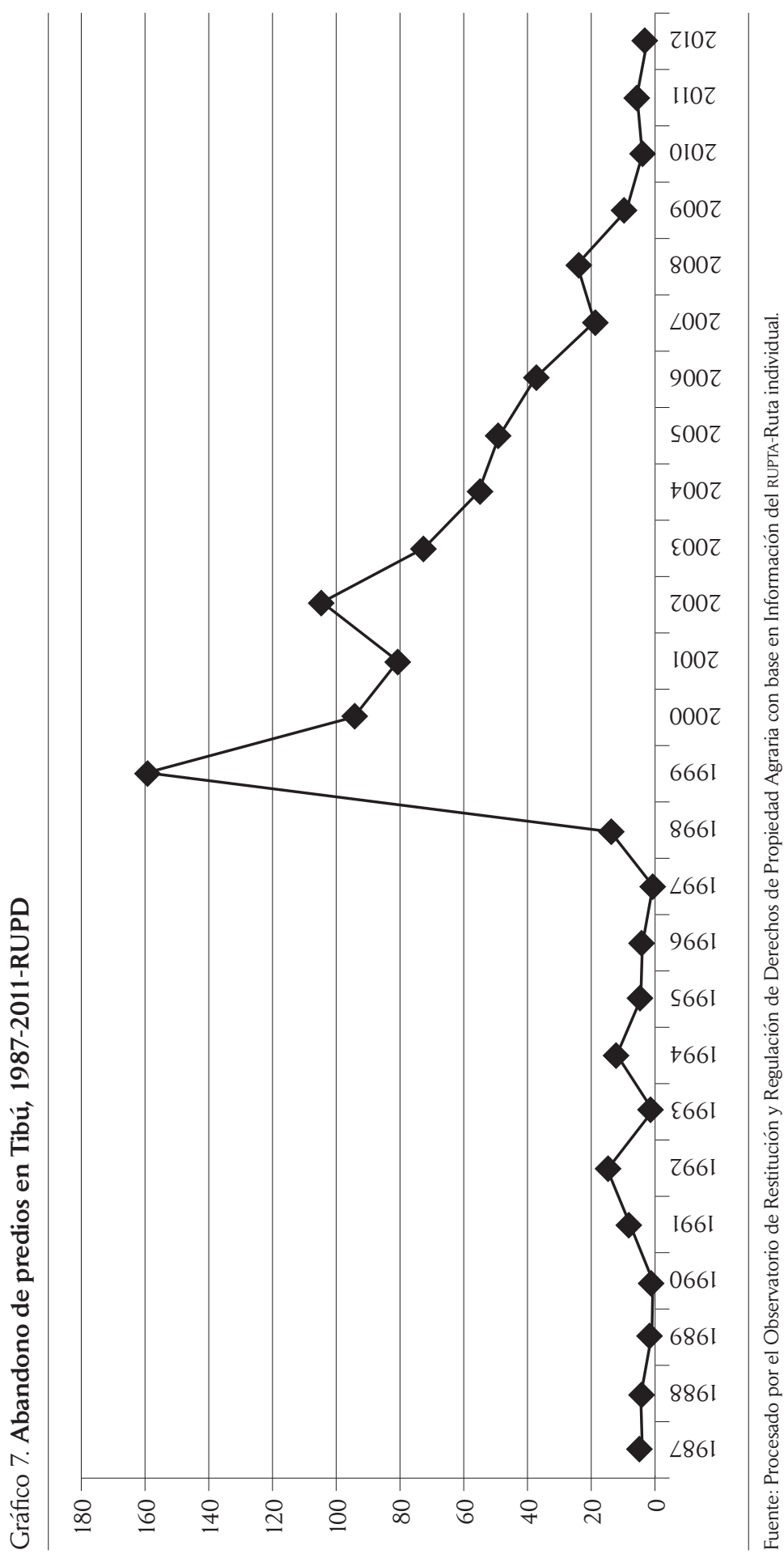


Mapa 3. ${ }^{21}$ Dinámica de compraventa de predios en Tibú (2005-2010)
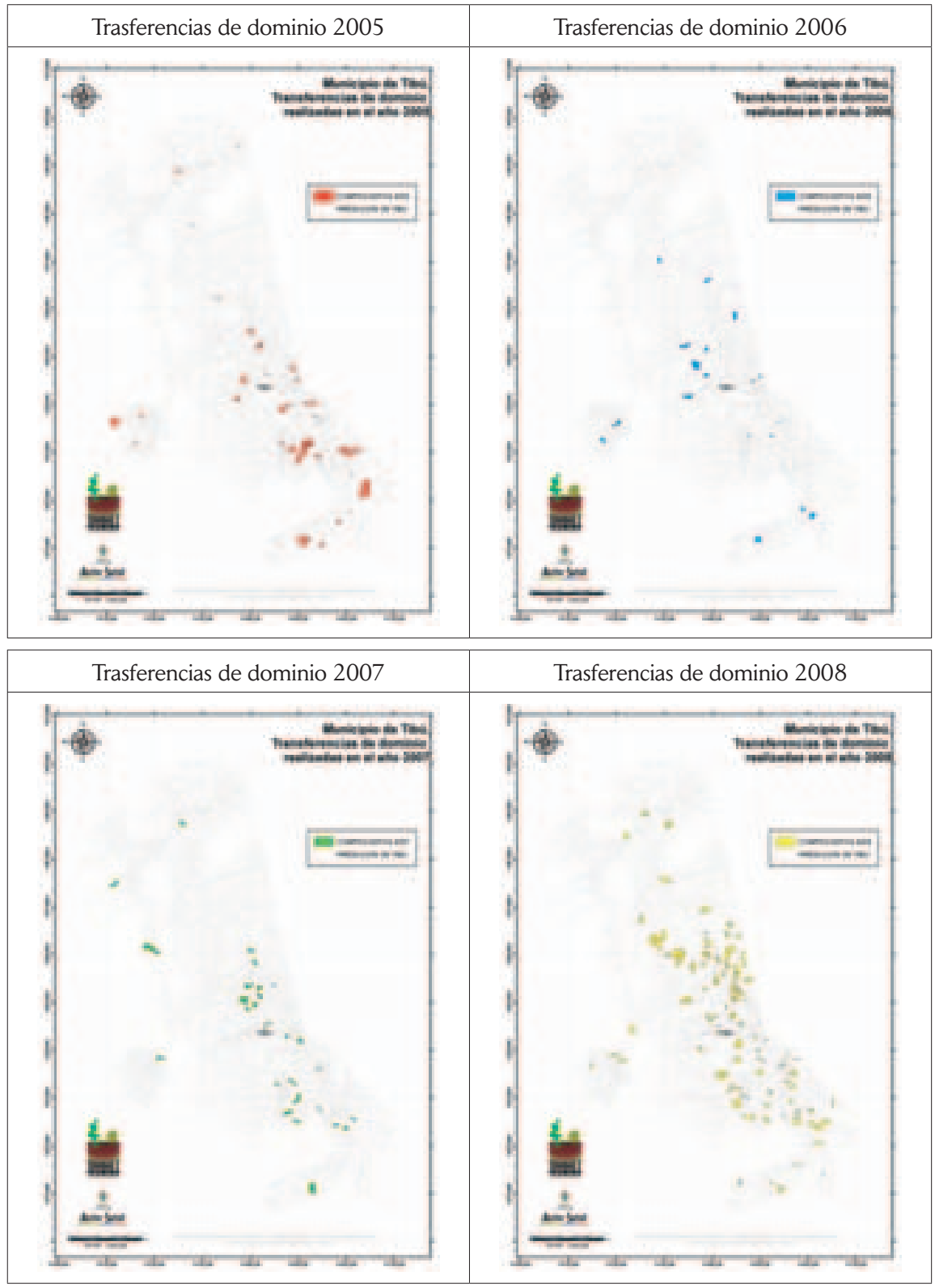

Continúa

el señor Peláez Dangond compró directamente en los lugares donde se encontraran los dueños, poseedores $u$ ocupantes de tierras y a cada uno de los vendedores, les hizo firmar un documento según el cual, si demandaban la compra, serían embargados" (Unidad Administrativa Especial..., s.f.).

21 Mapas facilitados a la autora por el equipo regional de Acción Social, PPTP-Norte de Santander (2010). 


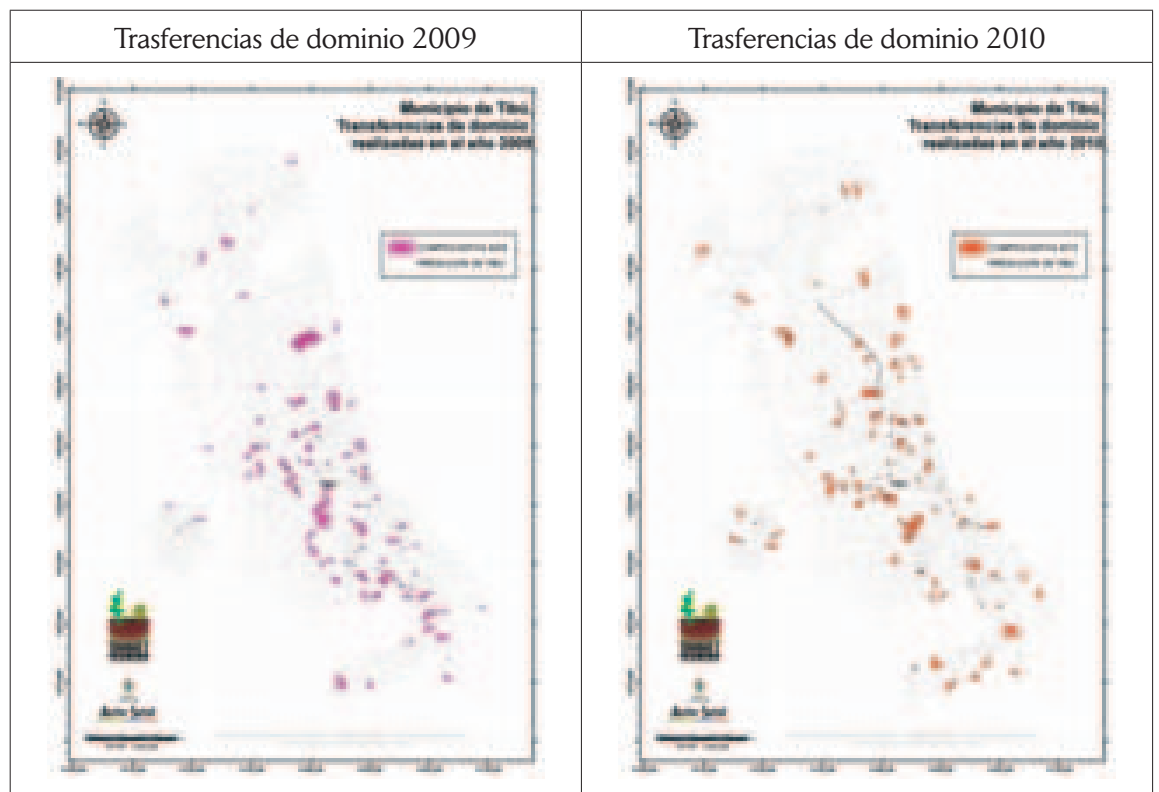

Fuente: Acción Social, Proyecto Protección de Tierras y Patrimonio de la Población Desplazada (PPTP), Norte de Santander.

La tierra se vendía muy barata porque esto era zona roja, incluso gente de aquí mismo compró tierra en su momento para sembrar palma. Luego esa tierra que se compró barata se puso muy cara, [...] ahora la tierra vale mucho, especialmente donde están los proyectos de la palma. La palma trajo bienestar a muchas familias campesinas en un momento, porque aquí había mucha pobreza y entonces la gente solo tenía como opción trabajar en los cultivos de coca [...] Mucha gente quisiera regresar pero, ahora, es difícil porque las tierras buenas cuestan mucho dinero y son para la palma [...] Aquí para lo único que se está promoviendo es para la palma [...] A mí me preocupa mucho que ya el municipio está dejando de producir alimentos, entonces la gente tiene que traer todo de fuera y como las ganancias de la palma se ven es en el largo plazo, entonces la gente se va nuevamente a lo de la coca. Es un ciclo muy complicado por la violencia que tenemos aquí (Uribe Kaffure, entrevista al entonces alcalde de Tibú, 2010).

Un estudio reciente de la Superintendencia de Notariado y Registro (SNR, 2012) evidenció que el 32\% de las compraventas de predios en vigencia de las medidas de protección se realizaron por empresas relacionadas 
con el cultivo de palma de aceite y explotaciones minero-energéticas. Tales empresas son consideradas por este organismo como 'compradores masivos', ya que han acumulado unidades agrícolas familiares de predios baldíos adjudicados a población campesina, en extensiones que superan el máximo de extensión permitido por la ley, de acuerdo con la Resolución 041 de 1969 (figura 5). El estudio de la Superintendencia calcula que mediante la compraventa masiva de predios los diversos compradores acumularon como mínimo 8.800 hectáreas (Superintendencia de Notariado y Registro, 2012; Salinas, 2011. El mapa 4 ilustra la magnitud del mercado desregulado entre 2005 y 2020 y el mapa 5, cuántos de esos predios habían nacido a la vida jurídica por adjudicaciones del Estado a pequeños campesinos. Un tema fundamental a tener en cuenta estriba en que las deudas adquiridas por los campesinos (antes de los hechos de desplazamiento) se convirtieron en un factor de negociación de la tierra por parte de los empresarios y comisionistas que operaron el mercado desregulado. ${ }^{22}$

Las figuras 5 y 6 ilustran algunas de las principales y sofisticadas formas en las que se acumularon indebidamente las UAF en Tibú:

- Acumulación de unidades agrícolas familiares.

- Registro de resoluciones de titulación o adjudicación que ya habían perdido su fuerza normativa y que por tanto no podían ser inscritas.

- Adscripción de UAF (con debido título y modo) al capital de empresas o asociaciones productivas, especialmente relacionadas con la agroindustria.

- Registro de resoluciones falsas de titulación (muchas de ellas basadas en información de resoluciones originales no registradas, a las que les cambiaban tanto el nombre de los adjudicatarios como el área titulada).

22 En entrevista realizada a funcionaria de la Gobernación de Norte de Santander y a enlace regional de Acción Social-PPTP (Uribe Kaffure, 2010) estos refirieron las deudas adquiridas por la población con Banco Agrario, como una de las estrategias a través de las cuales los comisionistas presionaban a la población en situación de desplazamiento a vender sus predios. 
Figura 5. Transacciones y figuras usadas en Tibú para la compra masiva y principales agentes

- Compraventa fraccionada de predios adjudicados como baldíos sin autorización de Incora/IIncoder, por debajo de la UAF.

- Nuevos predios conformados por matrices en los que uno de ellos proviene de dominio privado y otro de baldío (un predio de mayor extensión UAF).

- Tierras adjudicadas como baldíos aportadas a sociedades o comunidades que consolidan la propiedad sobre tales terrenos en superficies que excedan la UAF.

Las deudas de la PD fueron un factor de presión en la dinamización del mercado

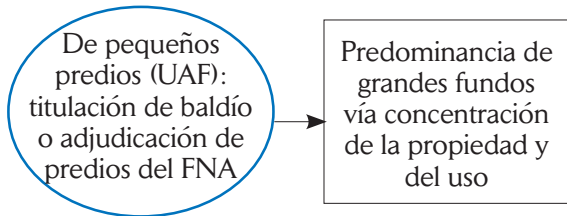

\begin{tabular}{|c|c|c|}
\hline \\
\hline \multirow{2}{*}{\multicolumn{2}{|c|}{ 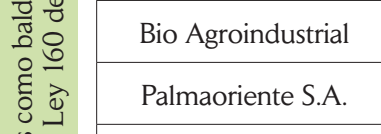 }} & 1.524 ha \\
\hline & & 5.587 ha \\
\hline \multirow{6}{*}{ 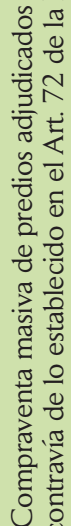 } & $\begin{array}{l}\text { Yinet paola Gutierrez } \\
\text { de Piñeres }\end{array}$ & 129 ha \\
\hline & $\begin{array}{c}\text { Edgar Rodrigo Rivera } \\
\text { Guiza }\end{array}$ & 266 ha \\
\hline & $\begin{array}{l}\text { Palmeros Aliados de } \\
\text { Colombia S.A. }\end{array}$ & 475 ha \\
\hline & Ecopalma & 50 ha \\
\hline & $\begin{array}{c}\text { Ganaderia Puerto Rico } \\
\text { Limitada }\end{array}$ & 771 ha \\
\hline & Total & 8.802 ha \\
\hline
\end{tabular}

Fuente: elaboración propia con base en: SNR (2011) y trabajo de campo (2010).

\section{A modo de cierre}

6.1. Los efectos e impactos del masivo abandono y despojo de tierras vía coerción y vía mercado anómalo y desregulad se ajustan más a las lógicas de expulsión (Sassen, 2013) y de acumulación por desposesión (Harvey, 2003) que al concepto de migración forzada del Derecho Internacional (DDHH y $\mathrm{DIH})$. Las transformaciones de los territorios alterados son estructurales y claramente concentradoras.

6.2. El caso evidencia que el despojo de los actores armados no necesariamente produce concentración de la propiedad agraria. Aunque quien despoja lo hace desde el incentivo de concentrar, en el caso de estudio el incentivo, por ejemplo, de la vía coercitiva era vaciar el territorio. Pero igualmente vemos cómo la concentración por vía de mercado sí transformó la estructura predial rural, poniendo en uso viejas y nuevas prácticas a través de las cuales se hace aprovechamiento de las fallas en la regulación estatal. 
1. Compraventa fraccionada de predios adjudicados como baldíos sin autorización de INCORA/INCODER, por debajo de la UAF.

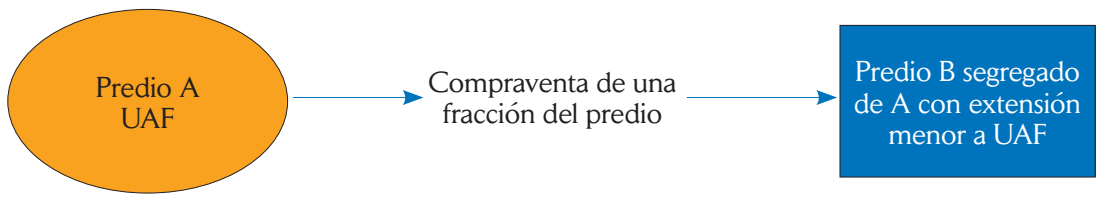

2. Creación de nuevos predios conformados por predios matriz en los que uno de ellos proviene de dominio privado y otro de baldío, resultando un predio de mayor extensión UAF.

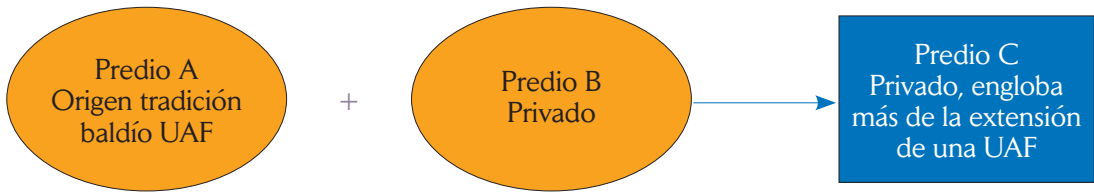

Compraventa y englobe

3. Tierras adjudicadas como baldíos aportadas a sociedades o comunidades que consolidan la propiedad sobre tales terrenos en superficies que excedan la UAF.
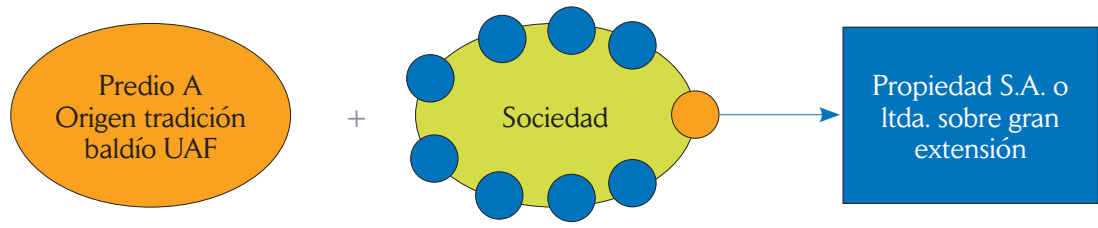

Aporte a capital

6.3. La política de incentivos estatales de explotación económica del territorio fue igualmente decisiva en las dos vías de acumulación-despojo.

6.4. Para el caso de estudio, la concentración por vía de mercado anómalo y desregulado es de todos modos despojadora a la luz de la Ley 1448 de 2011 y, adicionalmente, ilegal, a la luz de la Ley 160 de 1994, que prohíbe la acumulación de UAF.

6.5. En este caso particular hay ingentes ambivalencias estatales respecto de la asignación y regulación de derechos de propiedad agraria que hacen que haya inseguridad jurídica y que incentivan el despojo:

- Políticas distributivas: titulación de baldíos y adjudicación parcelaria

- Protección patrimonial 


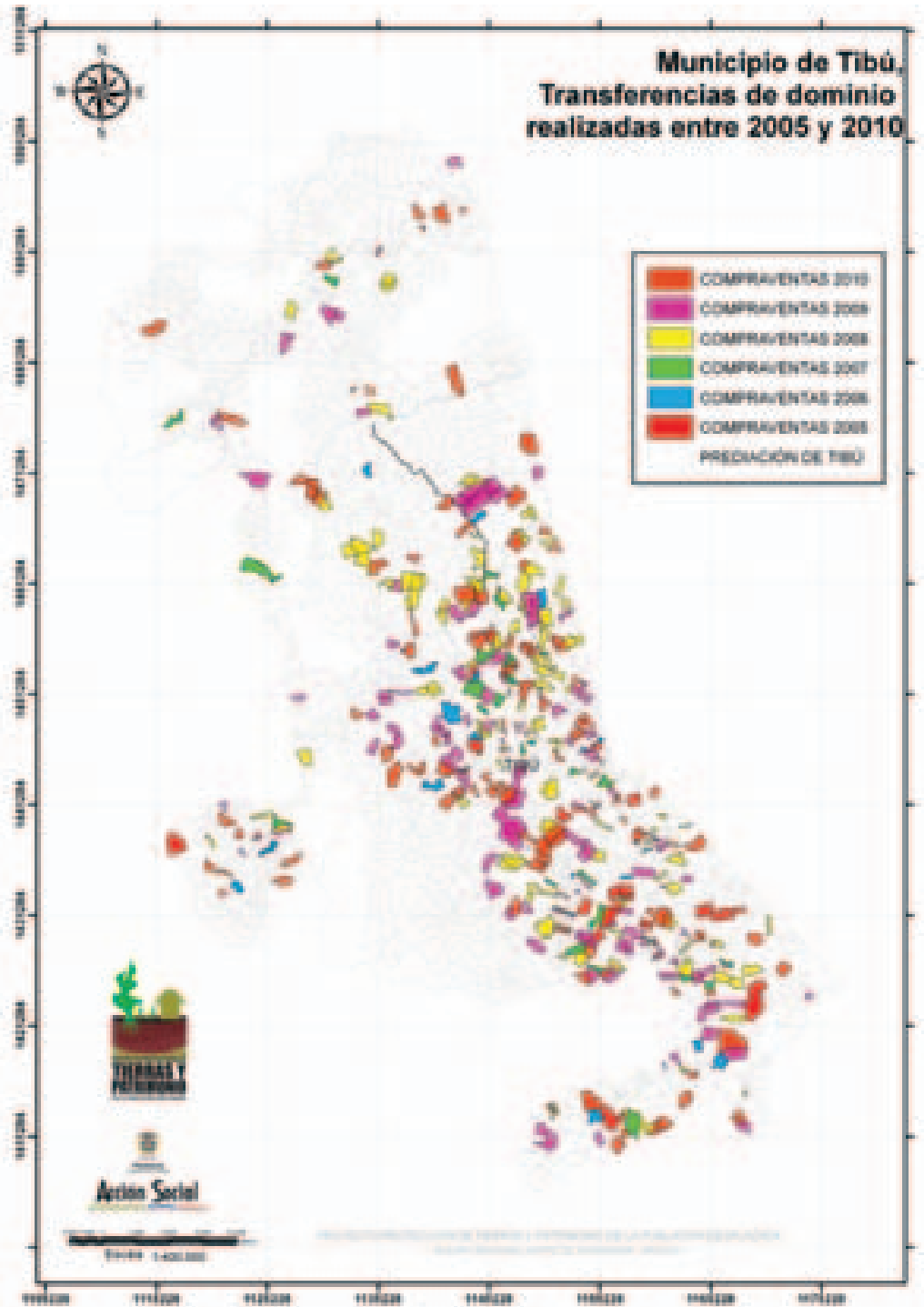

Fuente: Acción Social, PPTP-Norte de Santander (2010).

- Compraventa masiva de tierras (con o sin cumplir los requisitos)

- Incentivo a la inversión (acumulación de tierras por uso)

- Mercado activado por vía coercitiva, aunque no operado por el actor coercitivo. 


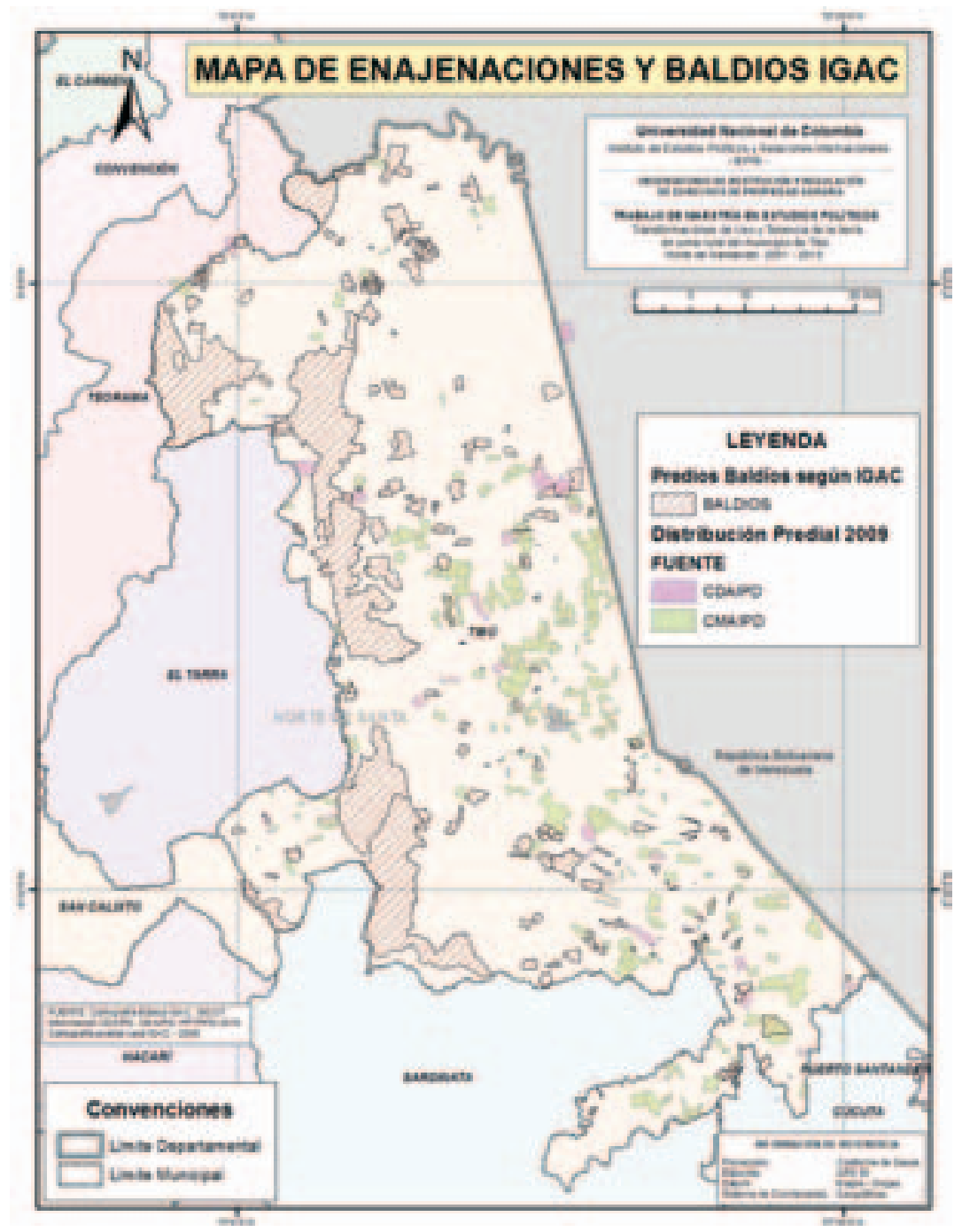

Fuente: elaboración propia con base en información suministrada por Acción Social, PPTP-Norte de Santander sobre trámites de enajenación y transferencia de predios con medida de protección colectiva (2005-2010).

6.6. Permitir la consolidación de estas transformaciones, aunque sea con el argumento del desarrollo económico, es validar la imposición violenta del latifundio como forma de organización del mundo rural, así como la 
expulsión-exclusión de la población rural campesina y sus formas tradicionales de producción.

\section{Reflexión final}

¿Dónde habrá de restituirse a las víctimas?, ¿sobre qué tierras? ¿Es posible devolver las unidades agrícolas familiares para el desempeño productivo y social de la pequeña y mediana economía campesina, tradicionalmente productora de alimentos? ${ }^{23}$

Estos interrogantes me llevan a otro que considero central: ¿es posible la restitución en medio del modelo concentrador que el país viene consolidando violentamente? A mi juicio, y al de muchos otros investigadores de altas cualidades e intachable trayectoria, no lo es.

Pese a las bondades de la Ley 1448 de 2011, este es un problema que supera la justicia transicional. Colombia necesita pensar en un modelo que redistribuya los activos rurales y haga viable su desarrollo económico y social, pues, claramente, el actual modelo no nos llevará por esa senda. Para el logro de soluciones duraderas para la paz se necesita una locomotora para la redistribución efectiva y justa de los activos rurales. El cómo redistribuir y desalambrar es el asunto en cuestión.

\section{Referencias}

\section{Bibliográficas}

Agencia Presidencial para la Acción Social y la Cooperación Internacional -Acción social-, Proyecto Protección de Tierras y Patrimonio de la Población Desplazada PPTP (2010a). Estudio de tenencia municipio de Tibú, Norte de Santander. Bogotá: Equipo de Comunicaciones.

Agencia Presidencial para la Acción Social y la Cooperación Internacional -Acción social-, Proyecto Protección deTierras y Patrimonio de la Población Desplazada

23 De acuerdo con la Unidad Territorial de Restitución de Tierras de Norte de Santander, Tibú es el tercer municipio con más tierras a restituir después de Carmen de Bolívar y Turbo (Laguado Nieto, 2013). 
PPTP (2010 b). La experiencia Colombiana en la salvaguarda de los derechos patrimoniales de las personas desplazadas internamente en contextos de violencia. Bogotá: Equipo de Comunicaciones.

Albán, A. (2011, primer semestre). Reforma y contrarreforma agraria en Colombia. Revista de Economía Institucional, 13(24), 327-356.

Asociación para la promoción social alternativa -Minga- (2008). Memoria: Puerta a la esperanza. Violencia sociopolítica en Tibú y El Tarra, región del Catatumbo 19982005. Recuperado de http://www.asociacionminga.org/pdf/libros/MemoriaPuertaalaEsperanza.pdf

Berry, A. (2012). La economía de la reforma agraria y las pequeñas granjas en los países en desarrollo: consecuencias para las situaciones posconflicto. En M. Bergsmo, C. Rodríguez, P. Kalmanovitz, y M. Saffon (eds.). Justicia distributiva en sociedades en transición (pp. 25-71). Oslo: Torkel Opsahl Academic EPublisher.

Bruce, J. W. (2000). Conceptos sobre tenencia de la tierra. En Tenure Brief 2000 (1s). Recuperado de http://ageconsearch.umn.edu/bitstream/12816/1/ltctb01s.pdf Centro de investigación y educación popular -Cinep- (1998). Colombia, país de regiones. Tomo II, Bogotá: Cinep-Colciencias.

Chonchol, J. (1967, abril-junio). El desarrollo de América Latina y la Reforma Agraria. Revista Mexicana de Sociología, 29(2), 257-327.

Chonchol, J. (1989, junio). El desarrollo rural y la reforma agraria en América Latina. Boletín de Estudios Latinoamericanos y del Caribe, (46), 3-15. Recuperado de Centrum voor Studie en Documentatie van Latijns Amerika (CEDLA) ArticleStable. Recuperado de http://www.jstor.org/stable/25675406

Comisión Nacional de Seguimiento a la Política Pública de Desplazamiento Forzado (2011). Cuantificación y valoración de las tierras y los bienes abandonados o despojados a la población desplazada en Colombia (pp. 17-59). En Comisión nacional de seguimiento a la política pública de desplazamiento forzado. El reto ante la tragedia humanitaria del desplazamiento forzado: reconocer y resarcir debidamente los daños y perjuicios. Bogotá: Torre Gráfica.

Consultoría para los Derechos Humanos y el Desplazamiento -Codhes- (2007). Respuesta Institucional al Desplazamiento Forzado en Norte de Santander: Cuando la Atención se Fragmenta en Cuatro Enfoques. Informe sobre conflicto armado, situación humanitaria y de desplazamiento forzado y la política pública de atención al desplazamiento forzado en 2007. Bogotá: Codhes.

Dinámicas recientes del conflicto armado en el Catatumbo (2010). Recuperado de http:// www.derechoshumanos.gov.co/Observatorio/Publicaciones/documents/2010/ EstudiosRegionales/catatumbo.pdf 
Fajardo, D. (2002, julio). Situación y perspectivas del desarrollo rural en el contexto del conflicto colombiano. Documento presentado ante el seminario "Situación y perspectivas para el desarrollo agrícola y rural en Colombia" FAO, Santiago de Chile.

Fajardo, D. (2009). Territorios de la agricultura colombiana. ( $1^{a}$ ed.). Bogotá: Universidad Externado de Colombia - Centro de Investigaciones sobre Dinámica Social. Fajardo, D. (2011, septiembre). Contribución del 'modelo' de desarrollo agrario a la crisis alimentaria. Conferencia expuesta ante la Academia Colombiana de Ciencias Económicas, Bogotá.

Fajardo, D. (s.f.). Poder político y reforma agraria y rural. Cuadernos Tierra y Justicia, (1). Recuperado de http://www.kus.uu.se/CF/Cuaderno_01.pdf

Gobernación de Norte de Santander (2000). Plan de Desarrollo Integral y Paz para la Región del Catatumbo. San José de Cúcuta: Plan Nacional de Desarrollo Alternativo - Red de Solidaridad Social - Ecopetrol.

Gutiérrez Sanín, F. (2010). Instituciones y territorio: la descentralización en Colombia. En F. Gutiérrez Sanín, V. Barberena, L. J. Garay, y J. M. Ospina (eds.). 25 años de la descentralización en Colombia. Bogotá: Fundación Konrad Adenauer.

Gutiérrez, F. y Barón, M. (2005). Estado, control territorial paramilitar y orden político en Colombia. Notas para una economía política del paramilitarismo, 19782004. En UN-Instituto de Estudios Políticos y Relaciones Internacionales. Nuestra Guerra sin nombre. Transformaciones del conflicto en Colombia. Bogotá: Universidad Nacional de Colombia - IEPRI.

Gutiérrez, F. y Barón, M. (2008). Órdenes subsidiarios. Coca, esmeraldas: la guerra y la paz. En: Colombia Internacional 67, 102-129.

Gutierrez Sanin, F. (2012). Desigualdad Extrema: una preocupación política. Las políticas rurales en Colombia en el periodo 2000-2009. En M.Bergsmo, C. Rodriguez, P. Kalmanovitz y M. Saffón (eds) Justicia Distributiva en Sociedades en Transición. (pp.233-265). Oslo:Torkel Opsahl Academic EPublisher.

Harvey, D. (2003). El nuevo imperialismo, Madrid: Akal, Madrid.

Ibáñez, A. M. y Querubín, P. (2004). Acceso a tierras y desplazamiento forzado en Colombia. Documento CEDE.

Ibáñez, A. M. y Muñoz, J. C. (2012). La persistencia de la concentración de la tierra en Colombia: ¿qué pasó entre 2000 y 2009? En M.Bergsmo, C. Rodriguez, P. Kalmanovitz y M. Saffón (eds) Justicia Distributiva en Sociedades en Transición. (pp.301-328). Oslo: Torkel, Opsahl Academic EPublisher.

Instituto Geográfico Agustín Codazzi-IGAC- (2006). Estudio General de Suelos y Zonificación de Tierras del Departamento de Norte de Santander. Bogotá: Imprenta Nacional de Colombia. 
Instituto Geográfico Agustín Codazzi -IGAC- (2008). Atlas Básico de Colombia, tomo II. (7 $7^{\text {a }}$ ed.). Bogotá: Imprenta Nacional de Colombia.

Instituto Geográfico Agustín Codazzi -IGAC- (2012). Atlas de la distribución de la propiedad rural en Colombia. Bogotá: Imprenta Nacional de Colombia.

LeGrand, C. (1988). Colonización y protesta campesina en Colombia (1850-1950). Bogotá: Centro Editorial Universidad Nacional de Colombia.

Lipton, M. (2009). Land Reform in Developing Countries. Property Rights and Property Wrongs. Nueva York: Routledge Priorities in Development Economics.

Machado, A. (1998). La cuestión agraria en Colombia a fines del milenio. Bogotá: El Ancora. Monografia Politico Electoral Departamento del Norte de Santander 1997-2007. Recuperado de http://moe.org.co/home/doc/moe_mre/CD/PDF/ndesantander.pdf

OCHA (2007). Ficha técnica, departamento de Norte de Santander (Catatumbo). Sala de Situación Humanitaria. Recuperado de http://www.colombiassh.org/site/IMG/ pdf/Ficha_Tecnica_Nortedesantander_08-07.pdf

Oquist, P. (1986). Violencia, conflicto y políticas en Colombia. Bogotá: Universidad de los Andes.

Pérez, E. y Farah, M. (s.f.). Los modelos de desarrollo y el desarrollo rural en América Latina. Foro Rural Mundial. Recuperado de http://www.fidamerica.org/admin/docdescargas/centrodoc/centrodoc_1190.pdf

Pérez, L. (2006, febrero). Comunidades del Catatumbo: entre el conflicto armado y la imposición de modelos de desarrollo regional. Revista Población CIVIL, 13-26.

Peña Huertas, R. P., Parada Hernández, M. M., Zuleta Ríos, S. La regulación agraria en Colombia o el eterno déjàvu. hacia la concentración y el despojo: un análisis de las normas jurídicas colombianas sobre el agro (1991-2010). Estudios Socio-Jurídicos 16 (1), pp. 121-164. doi: dx.doi.org/10.12804/esj16.12014.03

Polanyi, K. (2011).La gran transformación. Los orígenes políticos y económicos de nuestro tiempo. México: Fondo de Cultura Económica.

Programa Presidencial para los Derechos Humanos y el Derecho Internacional Humanitario (2004). Los Derechos Humanos en el Departamento Norte de Santander. Bogotá: Vicepresidencia de la República.

Reyes, A. (1978). Latifundio y poder politico. La hacienda ganadera en Sucre. Bogotá: Cinep, Serie Colombia Agraria.

Reyes, A. (1988). La violencia y el problema agrario en Colombia. Recuperado de http:// www.banrepcultural.org/blaavirtual/revistas/analisispolitico/ap2.pdf

Reyes, A. (2009). Guerreros y campesinos. El despojo de la tierra en Colombia. Bogotá: Norma. 
Ruiz, A., y Lozada, J. (2004). Marginalidad, riqueza y negación, conflicto, derecho a la educación y desplazamiento en el Catatumbo. Bucaramanga: FUNPROCEP.

Salinas, Y. y Zarama, J. (2012). Justicia y Paz: Tierras y territorios en las versiones paramilitares. Bogotá: Informe del Centro Nacional de Memoria Histórica.

Salinas Abdala, Y. (2011). Dinámica en el mercado de la tierra en Colombia. Documento elaborado para la Oficina Regional de la FAO para América Latina y el Caribe. Recuperado de http://www.indepaz.org.co/wp-content/uploads/2012/03/608_ COLOMBIA-TIERRAS-SALINAS-MAYO-11.pdf

Salinas Abdala, Y. (2011, 19 de marzo). El caso de Jiguamiandó y Curvaradó: iestrategia criminal vinculada a un modelo de desarrollo económico? Recuperado de http:// lasillavacia.com/historia-invitado/22660/yamile-salinas-abdala/el-caso-de-jiguamiando-y-curvarado-estrategia-criminal

Sassen, S. (2012). Expanding the Terrain for Global Capital. When Local Housing Becomes an Electronic Instrument. En M. Aalbers (ed.). Subprime Cities: The Political Economy of Mortgage Markets. New Jersey: Blackwell Publishing.

Serrano, M. (2009). Conflicto armado y cultivos ilícitos: efectos sobre el desarrollo humano en el Catatumbo. Bogotá: Ediciones Uniandes.

Suescún Barón, C. (2012). Determinantes de la dinámica reciente del uso y tenencia de la tierra en Colombia, 2002-2010. Una aproximación departamental (tesis de maestría). Bogotá: Universidad Nacional de Colombia, Facultad de Ciencias Económicas.

Superintendencia de Notariado y Registro (2012). Para que los colombianos recuperen su tierra (inédito). Informe de Norte de Santander. Bogotá: Superintendencia de Notariado y Registro.

Unidad administrativa especial de gestión de restitución de tierras despojadas (s.f.). Documento de análisis para uso interno No. 012, caso municipio de Tibú, departamento de Norte de Santander (inédito). Bogotá D.C.: UAEGRTD, grupo de registro y análisis de contexto - Dirección Social.

\section{Periodísticas}

Arranca desmovilización del bloque Catatumbo (2004, 28 de octubre). El Tiempo. Recuperado de http://www.eltiempo.com/archivo/documento/MAM-1531251 Así fue la incursión paramilitar en Norte de Santander (20013, 22 de abril). Recuperado de http://www.verdadabierta.com/justicia-y-paz/juicios/4556-asi-fue-laincursion-paramilitar-en-norte-de-santander 
Camilo, Armando Alberto Pérez Betancourt (2010, 20 de septiembre). Verdad Abierta. Recuperado de http://www.verdadabierta.com/victimarios/perfiles-deparamilitares/433-c/661-perfil-armando-alberto-perez-betancur-alias-camilo.

Denuncian amenazas a reclamantes de tierras en Norte de Santander (s.f.). El Tiempo. Recuperado de http://m.eltiempo.com/colombia/oriente/denuncian-amenazasa-reclamantes-de-tierras-en-norte-de-santander/12092647

El ABC del Catatumbo (2004, 14 de noviembre). Revista Semana. Recuperado de http://www.semana.com/on-line/articulo/el-abc-del-catatumbo/69260-3

El cartel de Mancuso (2009, 7 de mayo). Verdad Abierta. Recuperado de http://www. verdadabierta.com/justicia-y-paz/extraditados/1208-el-cartel-de-mancuso

El Ejército abrió el Catatumbo a los paras (2009, 5 de Julio). Revista Semana. Recuperado de http://www.semana.com/nacion/articulo/el-ejercito-abrio-catatumboparas/104811-3. Recuperada abril de 2013.

El Iguano, Jorge Iván Laverde Zapata (2008, 30 de diciembre). Verdad Abierta. Recuperado de http://www.verdadabierta.com/victimarios/perfiles-deparamilitares/443-m/704-prueba

El Iguano condenado por masacres y asesinatos políticos (2010, 2 de diciembre). Verdad Abierta. Recuperado de http://www.verdadabierta.com/justicia-y-paz/ juicios/2895-el-iguano-condenado-por-masacres-y-asesinatos-politicos

"La fuerza pública fue clave para la expansión de las Auc": Mancuso (2012, 14 de marzo). Verdad Abierta. Recuperado de http://www.verdadabierta.com/justiciay-paz/versiones/382-el-mono-mancuso-salvatore-mancuso/3932-qla-fuerza-publica-fue-clave-para-la-expansion-de-las-aucq-mancuso

Laguado Nieto, O. E. (2013, 4 de marzo). Tierra en Disputa. Recuperado de http://www. verdadabierta.com/component/content/article/48-despojo-de-tierras/4457tierra-en-disputaDespojo-Despojo de tierras

Los archivos secretos (2005, 3 de diciembre). Revista Semana. Recuperado de http:// www.semana.com/nacion/articulo/los-archivos-secretos/75453-3

Ser 'sapos' será una carga que aguantaremos toda la vida (2011, 9 de septiembre). El Espectador. Recuperado de http://www.verdadabierta.com/victimarios/jefesde-la-auc/1599-qser-sapos-sera-una-carga-que-aguantaremos-toda-la-vidaq-elespectador

Silva, S. (2012, 28 de diciembre). Aceite de palma, de Tibú a Holanda. El Espectador. Recuperado de http://www.elespectador.com/noticias/nacional/articulo394391-aceite-de-palma-de-tibu-holanda 
Tierras de buena y de mala fe (2013, 5 den junio). El Espectador. Recuperado de http:// www.elespectador.com/noticias/politica/articulo-426161-tierras-de-buena-y-demala-fe, consultado el 13 de octubre de 2013.

Un acto de fe (2004, 5 de diciembre). Revista Semana. Recuperado de http://www. semana.com/nacion/articulo/un-gran-acto-fe/69761-3 
Anexos

Anexo 1.Cobertura predial rural de Tibú (1999-2009)

\begin{tabular}{|c|c|c|c|c|c|}
\hline \multirow{2}{*}{ Año } & \multicolumn{5}{|c|}{ Rango predial (ha) } \\
\cline { 2 - 6 } & $<10$ & $10-50$ & $50-200$ & $200-1.000$ & $>1.000$ \\
\hline 1999 & 2.582 & 45.537 & 128.180 & 37.675 & 43.496 \\
\hline 2000 & 2.571 & 47.021 & 128.057 & 36.162 & 43.496 \\
\hline 2001 & 2.480 & 47.406 & 128.699 & 35.286 & 43.496 \\
\hline 2002 & 2.381 & 47.545 & 128.907 & 35.073 & 43.496 \\
\hline 2003 & 2.410 & 47.664 & 128.460 & 35.331 & 43.496 \\
\hline 2004 & 2.407 & 47.903 & 128.275 & 35.367 & 43.496 \\
\hline 2005 & 2.408 & 48.153 & 128.247 & 35.153 & 43.496 \\
\hline 2006 & 2.451 & 48.916 & 128.426 & 34.375 & 43.463 \\
\hline 2007 & 2.455 & 48.989 & 128.329 & 34.375 & 43.463 \\
\hline 2008 & 2.410 & 48.781 & 127.209 & 34.089 & 43.463 \\
\hline 2009 & 2.463 & 47.115 & 132.217 & 40.398 & 49.793 \\
\hline
\end{tabular}

Fuente: Adaptada de Acción Social - PPTP (2010), Estadísticas Catastrales IGAC (actualización 2009 disponibles Acción Social - PPTP, Norte de Santander)

\section{Anexo 2. Número de predios rurales de Tibú (1999-2009)}

\begin{tabular}{|c|c|c|c|c|c|c|c|c|c|c|c|}
\hline Rango & 1999 & 2000 & 2001 & 2002 & 2003 & 2004 & 2005 & 2006 & 2007 & 2008 & 2009 \\
\hline$<10$ & 1.633 & 1.637 & 1.546 & 1.465 & 1.261 & 1.258 & 1.258 & 1.279 & 1.280 & 1.221 & 5.616 \\
\hline $10-50$ & 1.602 & 1.668 & 1.677 & 1.684 & 1.688 & 1.695 & 1.705 & 1.732 & 1.735 & 1.724 & 1.632 \\
\hline $50-200$ & 1.391 & 1.391 & 1.399 & 1.400 & 1.396 & 1.395 & 1.395 & 1.395 & 1.396 & 1.385 & 1.393 \\
\hline $200-1.000$ & 131 & 127 & 124 & 123 & 124 & 124 & 124 & 121 & 121 & 120 & 143 \\
\hline$>1.000$ & 8 & 8 & 8 & 8 & 8 & 8 & 8 & 8 & 8 & 8 & 10 \\
\hline TOTAL & 4.765 & 4.831 & 4.754 & 4.680 & 4.477 & 4.480 & 4.490 & 4.535 & 4.540 & 4.458 & 8.794 \\
\hline
\end{tabular}

Fuente: Adaptada de Acción Social -PPTP (2010); Estadísticas Catastrales IGAC (actualización 2009) 
